\title{
Perspectives on care and communication involving incurably ill Turkish and Moroccan patients, relatives and professionals: a systematic literature review
}

Fuusje M de Graaff ${ }^{1,2}$, Patriek Mistiaen ${ }^{3 *}$, Walter LJM Devillé 1,3,5 $^{2}$ and Anneke L Francke $e^{3,4}$

\begin{abstract}
Background: Our aim was to obtain a clearer picture of the relevant care experiences and care perceptions of incurably ill Turkish and Moroccan patients, their relatives and professional care providers, as well as of communication and decision-making patterns at the end of life. The ultimate objective is to improve palliative care for Turkish and Moroccan immigrants in the Netherlands, by taking account of socio-cultural factors in the guidelines for palliative care.

Methods: A systematic literature review was undertaken. The data sources were seventeen national and international literature databases, four Dutch journals dedicated to palliative care and 37 websites of relevant national and international organizations. All the references found were checked to see whether they met the structured inclusion criteria. Inclusion was limited to publications dealing with primary empirical research on the relationship between socio-cultural factors and the health or care situation of Turkish or Moroccan patients with an oncological or incurable disease. The selection was made by first reading the titles and abstracts and subsequently the full texts. The process of deciding which studies to include was carried out by two reviewers independently. A generic appraisal instrument was applied to assess the methodological quality.

Results: Fifty-seven studies were found that reported findings for the countries of origin (mainly Turkey) and the immigrant host countries (mainly the Netherlands). The central themes were experiences and perceptions of family care, professional care, end-of-life care and communication. Family care is considered a duty, even when such care becomes a severe burden for the main female family caregiver in particular. Professional hospital care is preferred by many of the patients and relatives because they are looking for a cure and security. End-of-life care is strongly influenced by the continuing hope for recovery. Relatives are often quite influential in end-of-life decisions, such as the decision to withdraw or withhold treatments. The diagnosis, prognosis and end-of-life decisions are seldom discussed with the patient, and communication about pain and mental problems is often limited. Language barriers and the dominance of the family may exacerbate communication problems.

(Continued on next page)
\end{abstract}

\footnotetext{
* Correspondence: p.mistiaen@nivel.nl

${ }^{3}$ NIVEL (Netherlands Institute for Health Services Research), PB 15683500 BN, Utrecht, the Netherlands

Full list of author information is available at the end of the article
} 
(Continued from previous page)

Conclusions: This review confirms the view that family members of patients with a Turkish or Moroccan background have a central role in care, communication and decision making at the end of life. This, in combination with their continuing hope for the patient's recovery may inhibit open communication between patients, relatives and professionals as partners in palliative care. This implies that organizations and professionals involved in palliative care should take patients' socio-cultural characteristics into account and incorporate cultural sensitivity into care standards and care practices.

Keywords: Palliative care, Communication, Immigrants, Ethnic minorities

\section{Background}

Palliative care has seen considerable development in Western countries in the past few decades, and the number of hospices and other institutions specializing in palliative care has been growing [1-3]. Initially palliative care was mainly associated with care for terminally ill cancer patients. In recent years however, palliative care has expanded, including patients with non-malignant, progressive and life-limiting conditions such as heart failure and COPD [4]. Furthermore, palliative care providers and researchers increasingly pay attention to patients with specific cultural and sociodemographic characteristics, such as patients with a nonWestern background. This is illustrated by the fact that in 2002 the World Health Organization clearly stated that guidelines on palliative care in all countries have to be adapted to cultural contexts [5].

Studies of palliative care conducted in non-Western countries have pointed to patients' limited choices with regard to obtaining adequate pain relief and medication because of poverty [6-8]. Family care systems, religious practices and traditional care perceptions may influence the use of palliative care. Cultural minorities living in Western countries may face inadequate palliative care because of language differences [9], health literacy difficulties [10] or experiences of discrimination $[11,12]$. The supply of palliative care may not always meet the care expectations of immigrants due to their specific cultural or religious background [13-15]. Research among Sikh and Muslim patients with life-limiting illnesses living in Europe revealed that these immigrant patients are often reluctant to seek help from professional caregivers or institutions, rather than care from their own family and close relatives, because of negative experiences with care services (such as unacceptable food and racism) and concern about criticism from their community. Besides, communication with professionals was often hampered since illness and suffering were viewed as God's will [16].

In our empirical research in the Netherlands over the period 2001 to 2009 we found care professionals often see specific care needs and communication problems when delivering palliative care to immigrant patients $[17,18]$. They often find it difficult to assess and meet the needs of these patients and their families, due to the patient's lack of knowledge about the disease, cultural patterns within family relationships and inadequate formal or informal interpreter facilities. Turkish and Moroccan people form the largest immigrant groups in the Netherlands [19]. The ethnic roots of Turkish and Moroccan immigrants are diverse. However, most of them share important features such as coming from poor agricultural regions, arriving as low-paid 'guest workers' between 1965 and 1980, and living in deprived neighbourhoods as a Muslim minority. The first generations of Turkish and Moroccan immigrants are ageing now, and more and more of these people will start to need palliative care. An earlier literature study on the care needs of the Turkish and Moroccan elderly revealed that they often experienced barriers to making use of Dutch professional care, e.g. because of the strong role of family care in their cultures [20]. However, at that time we did not find any publications about Turkish and Moroccan people in the palliative phase. Since the number of patients in these groups needing palliative care will have increased since then, and accordingly the number of relevant studies can be expected to have grown, we decided to reinvestigate the international literature on Turkish and Moroccan incurably ill patients.

The questions addressed in this systematic literature review are:

What is known from previous research about

a) the care experiences and care perceptions of incurably ill Turkish and Moroccan patients, their relatives and care professionals?

b) communication between these patients, relatives and care professionals regarding care and treatment in the palliative phase?

\section{Methods}

A systematic review was performed in several steps to find research literature about care perceptions and communication in the care for Turkish or Moroccan incurably ill patients. In this review we used the term incurably ill Turkish or Moroccan patients' to refer to people with a Turkish or Moroccan background, whether living in Turkey or Morocco or living in the Netherlands or another immigrant host country, who suffer from an incurable 
life-threatening disease. A person is defined as having a Turkish or Moroccan background if they were 'born in Turkey or Morocco (with at least one parent born in Turkey or Morocco) or born outside Turkey or Morocco but with at least one parent born in Turkey or Morocco'.

\section{Searches}

We searched for both qualitative and quantitative studies. Three main sources were used to find the literature: 17 national and international literature databases, four Dutch journals dedicated to palliative care and 37 websites for relevant national and international organizations. Additional file 1 gives the details of all sources. Additionally, members of the project team were asked for relevant publications and references listed in review articles were checked. The search string below was used for Pubmed. Searches for the other databases were derived from this Pubmed search string and adjusted where necessary (these are available on request).

("End-of-life" OR palliative OR hospice OR dying OR
death OR "Advance Care Planning"[Mesh] OR
"Hospice Care"[Mesh] OR "Palliative Care"[Mesh] OR
"Withholding Treatment"[Mesh] OR "Terminal
Care"[Mesh] OR "Euthanasia"[Mesh] OR "palliative
sedation" OR "truth telling" OR "truth disclosure" OR
"advance directives") AND (culture specific* OR
culturally specific* OR diversity specific* OR culture
sensitive* OR culturally sensitive* OR diversity
sensitive* OR culturally divers* OR cultural aspect*
OR cultural competen* OR "cultural context" OR
racial OR etnic minorit* OR etnic specific* OR ethnic
minorit* OR ethnic specific* OR "ethnic background"
OR "etnic background" OR cross?cultural OR
crosscultural OR trans?cultural OR transcultural OR
intercultural OR inter?cultural OR multicultural OR
multi?cultural OR indigeneous OR indiginous OR
immigrant* OR migrant* OR ethnicity OR
acculturation OR islam* OR Muslim* OR Hindu* OR
Winti OR (Moroc* [tiab] OR Maroc* [tiab] OR Turk*
[tiab] OR Surinam* [tiab] OR Antill* [tiab] OR
aruba* [tiab] OR caribb* [tiab])) AND
("2000"[PDAT] : "2010"[PDAT])

Manual searches were performed in specific journals (see Additional file 1). Relevant websites were searched without a predefined search strategy. Searches were limited to publications dating from 2000 onwards, since we found little relevant literature on the topic in our earlier literature study [20]. No language restrictions were applied. Although the searches were initially somewhat broader and aimed at finding literature on five immigrant groups in the Netherlands (see the search string above), it appeared that very few publications could be traced about the other three immigrant groups, so we restricted the inclusion criteria further to just Turkish and Moroccan people for the purpose of this paper.

\section{Inclusion and exclusion criteria}

All the references obtained in this way were then checked to see whether they met the inclusion criteria. This was done first on the basis of the title/abstract and later on the basis of the full text of the documents. The inclusion process was carried out by two reviewers independently and disagreements were solved by discussion.

The inclusion criteria applied were as follows:

- It is a primary empirical research paper.

- The publication is about socio-cultural factors concerning Turkish or Moroccans subjects.

Socio-cultural factors are factors that might affect the feelings and behaviours of groups with regard to care values and care practices, family and kinships structures as well as their attitude towards professional care. We included publications on Turkish and Moroccan patients in their countries of origin in addition to publications on Turkish and Moroccan immigrants in host countries.

- A relationship between a socio-cultural factor and health (or care) outcomes was studied.

- The paper concerns patients and/or carers of patients with an oncologic or incurable disease and/or in the palliative phase.

Exclusion criteria were letters/editorials, publications on organ donation, perinatology, near-death experiences, death row or mourning. All searches were done in May 2010. The inclusion flow diagram is depicted in Figure 1.

\section{Appraisal of the methodological quality}

The methodological quality of the studies satisfying the inclusion criteria was checked. Since publications using different types of research methods (both qualitative and quantitative) were included, a generic appraisal instrument was applied [21]. This was chosen because it was specifically developed to appraise publications of disparate kinds of data. It consists of nine items (abstract, background, method, sampling, data analysis, ethics, results, transferability and implications); each item is scored on a 4-point scale from very poor to good (total scores may vary from 9 to 36; scores less than or equal to 18 were considered as 'poor methodological quality', from 19 to 27 'moderate' and above 27 'good quality'). The methodological assessment was done by one researcher $[\mathrm{PM}]$ and $50 \%$ of the references were also checked independently by a second reviewer [AF, WD] (in this case the mean of the two scores was computed). Reviewers were assigned in such a way that they never 


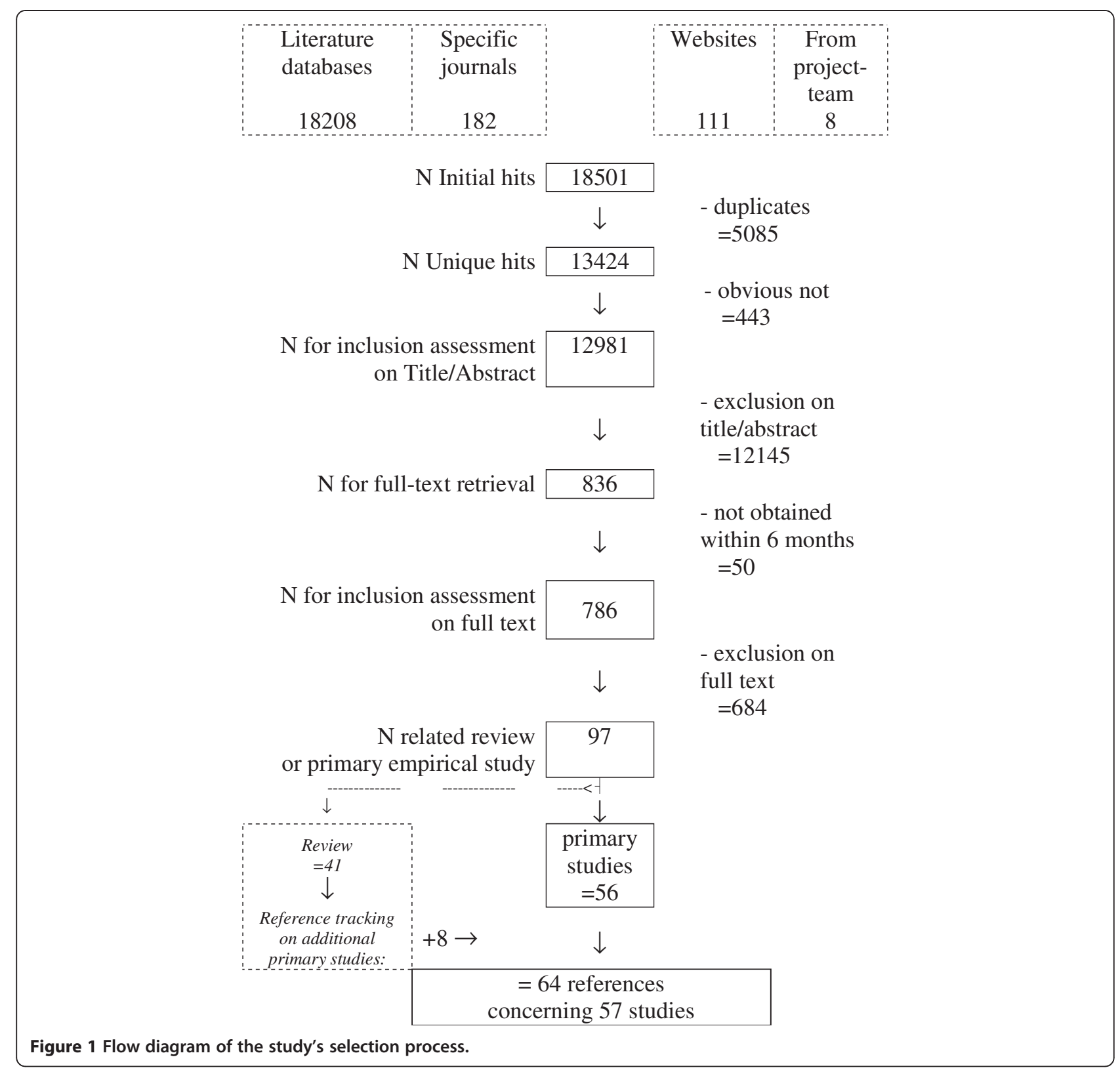

had to judge documents of which they were a co-author. The publications in the Turkish language were assessed by a native Turkish psychologist. A low methodological score was not used as an exclusion criterion, but studies with such a low score were checked if they presented results that contradicted the results in other studies.

\section{Data extraction, analysis and synthesis}

Data were extracted from each included publication by one reviewer and checked by a second. Data were extracted about the type of research, nature and size of the research population (ethnic group, professionals/patients/relatives, disease), country where the research was done, research questions and results.
Data from the publications that related to the review questions were extracted and classified in themes, which were then discussed in the research team. We analysed and synthesized the data in various ways, looking for contrasts: between Turkish and Moroccan patients, between experiences in countries of origin and experiences in host countries, between different care belief issues, between issues concerning care in practice and communication issues, and between the different phases that patients go through in the course of their illness. We concluded that the relevant data could best be presented in using the themes shown in Tables 1, 2, 3 and 4. For each theme, data from different populations (Turkish/Moroccan/mixed group of immigrants) and perspectives (patients/relatives/professionals) 
Table 1 Findings relating to perspectives on family care

\begin{tabular}{ll}
\hline Study & Family care as a duty \\
\hline Findings concerning Turkish patients & \\
(Aksoy, 2005) [28] & It was important for a traditional \\
& $\begin{array}{l}\text { Turkish family to look after ill and } \\
\text { old parents. Family care was a duty. }\end{array}$
\end{tabular}

(De Meyere, 2004) [47] $-$

(Groen-van de Ven and Smits, 2009) 2009 [55]

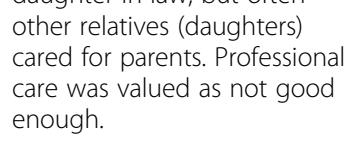
other relatives (daughters) cared for parents. Professional care was valued as not good enough. eldest son, cared for by their daughter-in-law, but often

(Oksuzoglu et al., 2006) [68]

The role of family and social factors was very great in Turkey.

(Van den Bosch, 2010) [77]

(Yerden, 2000) [80]

(Yerden, 2004) [81] $-$

$$
\begin{aligned}
& \text { Turkish active elderly } \\
& \text { expected their children } \\
& \text { (eldest son and wife) } \\
& \text { to take care for them. } \\
& \text { Their sons felt obliged } \\
& \text { to do so, but hoped } \\
& \text { to share this task with } \\
& \text { all the family. }
\end{aligned}
$$

Ideally elderly live with their son's family, many don't. Daughters (in law) mainly do caring. When elderly are active they suppose family will care, when they become bedridden family care turns out to be insufficient.
Family care as an economic necessity

Some women had financial problems, e.g. they could not pay for a breast prosthesis.

$-$

Financial situation limited self efficacy in Turkish elderly. $-$
Turkish elderly were often cared for by their children, but some children moved to other towns to flee from the heavy duty.

Children support elderly by shopping, cleaning, administration, cooking and personal care.

Women became depressed if they had no family, feared losing their husband, or tasks (preparing food, housekeeping, accompanying patients to doctors, and personal care). Relatives became overloaded when practices did not correspond with their norms.

and personal care. Family care involved a lot of

Findings concerning Moroccan patients

(Errihani et al., 2005) [52]

(Errihani et al., 2006) [50]
92\% of patients were supported by family members.

92\% of patients were helped by their family.
For many families monthly revenues were not enough to pay for treatments, only $15 \%$ were insured.

Poverty and lack of medical insurance limit professional treatments.

Findings regarding Turkish and Moroccan patients ( sometimes other immigrant patients as well)

(De Graaff and Francke,

2003a) [17]
'You should care for sick' was an ideal, but also a must, enforced by fear of gossip in the community. Male relatives often rejected help from outside family. Professional help was more accepted when women were active in decision-making process.
Even in large extended families daily physical care was often carried out by one female family member. 
(De Graaff and Francke,

2009) [45]

(Meulenkamp et al., 2010) [65]

(Korstanje, 2008) [60]

(NOOM, 2009) [23]

(VPTZ, 2008b) [26]

(Yerden and Van Koutrike, 2007) [82]
Many elderly expected their children to care for them and to prepare and offer food as soon as visitors arrive.

Patients preferred to be cared for by their kin. Talking about illness and the sorrow it brings was often not done in Turkish and Moroccan families.

Relatives felt responsible for patients and neglected duties regarding their work or children.

Parents and children created a dilemma: the ideal of children taking care of parents prevented them from looking for other solutions for meeting care needs.

Family care was an obvious response to a new situation, since immigrants often had no experience with dying people and did not know the supporting facilities in Netherlands. Turkish elderly often lived with a son or daughter, Moroccan families sometimes brought a helper from Morocco.

Men felt responsible for organizing care, but physical care and housekeeping was done by women.
Limited use of home care often led to high care burden for relatives and improper care.

The financial situation of immigrant elderly was often bad. Many elderly depended on their children for administration and financial management.

Family care sometimes led to financial problems. Relatives felt overburdened, but not able to discuss this as family care is obviously expected in their culture. were described and summarized. If possible, a distinction was made between the different immigrant groups and between data concerning the countries of origin and data concerning the immigrant host countries.

\section{Results}

\section{Characteristics of the studies included}

Sixty-four publications [17,18,20,22-83] were included concerning 57 studies. Some studies were presented in more than one publication. In those cases we used the main publication for the description of the characteristics and study findings.

\section{Language and place of study}

All studies were published in the period 2000 to 2010. Most of the 57 studies were published in English (39), one was in French [52] one in German [56], two were in Turkish $[31,64]$, and fourteen in Dutch. 
Table 2 Findings relating to perspectives on professional care

\begin{tabular}{ll}
\hline Study & Preferences for hospital care \\
\hline Findings concerning Turkish patients \\
(Aksoy, 2005) [28] & General public: 47\% would not send \\
& relatives to hospices, as it did not fit \\
& with traditional views on family duties; \\
& $54 \%$ would prefer to stay at hospital in \\
& their terminal phase. \\
& Health professionals: 55\% would not \\
& wish relatives to stay in a hospice; \\
& $64 \%$ would prefer to stay at home \\
& in terminal phase, since not much \\
& can be done in hospitals for patients \\
& in their terminal phase. \\
& In cases where treatment fails 43\% of \\
& gynaecological cancer patients would \\
& prefer inpatient care, $41 \%$ outpatient \\
care, 16,2\% wished to go home. Main \\
reason was feelings of security (90\%). \\
(Beji et al., 2005) [32]
\end{tabular}

(Cobanoglu and Algier 2004) [40]

(De Meyere, 2004) [47]

(Ersoy and Gundogmus, 2003) [54]

(Meric and Elcioglu, 2004) [64]

(Van den Bosch, 2010) [77] -

Most GPs preferred to hospitalize patients, even by using force if necessary, in order to keep them from harm.

Physicians were more often inclined to fulfil wishes of patients' family, than to respect patients' wishes, living will or previous consent of patient.

$33 \%$ of nurses preferred patients dying at home, $45 \%$ preferred patients dying in special facilities in hospitals and 22\% preferred wards exclusively for terminally ill people.

(Oflaz et al., 2010) [67]
Barriers to use of professional care /

Perspectives on quality of

professional care

Turkish elderly had little experience with and knowledge about palliative care. They would like to have Turkish-speaking personnel, flexible Ivisiting hours, separate wards for male and female patients, no pork meat and accommodation for Muslim burial rituals.

Physicians' most mentioned problem in category of 'social problems' was limited resources of hospitals (49\%).

Groups for mutual help among migrant women were not effective as women did not feel socially safe within these groups.

Talking to doctors was more comfortable as they are medical experts, who vowed secrecy. professionals and patient and relatives should be improved.
Teamwork within hospitals and communication between $64 \%$ of nurses thought psychiatrists should be working in palliative care, $18 \%$ opted for a palliative team comprising doctors, nurses, psychiatrists and relatives; 18\% opted for a team including dieticians and physiotherapists.

$27 \%$ of nurses experienced difficulties in dealing with problems like unrelieved pain and suffering of patients, and their own sadness and anxiety; $61 \%$ felt they experienced inadequacy and helplessness about pain management and treatment; $29 \%$ experienced difficulties with emotional distress, e.g. when patients or relatives denied their situation, were dissatisfied or refused treatment.

Many Turkish elderly had language problems when visiting GP. All patients having home care, used care from a Turkish home care organization.

$66 \%$ had been visiting doctors in Turkey, but these visits were expensive.

Most Turkish elderly preferred using care in Netherlands, for insurance reasons and because care seemed better in Netherlands. 
Table 2 Findings relating to perspectives on professional care (Continued)

(Yerden, 2000) [80]

(Yerden, 2004) [81]

Findings concerning Moroccan patients

(McCarthy et al.,

2004) [63]

(Errihani et al., 2005) [52]

(Errihani et al., 2006) [50]
Elderly were too ashamed to ask for professional care. They accepted use of GP and hospital, but not use of home care and old people's homes. Children were less negative about care provisions, but realized it would induce gossiping.

Home care and old people's homes were becoming more accepted, daughters (in law) were more willing to use provisions than sons.

Nurses and physicians working in oncology centres felt embarrassed by shortage of means and training in treatment of cancer-related pain.

Poverty and illiteracy were major obstacles for patient care. Alternative treatment were visiting marabouts, fqihs, using medical plants

Poverty and lack of medical insurance limited effective treatments: $85 \%$ of patients had no medical insurance and $52 \%$ had an income below $1500 \mathrm{DH}$ per month whereas cost of disease was $>35000 \mathrm{DH}$ in $85 \%$ of cases.

Chemotherapy was difficult to accept $(90 \%)$, radiotherapy (54\%) and surgery (40\%) were more accepted.

Findings regarding Turkish and Moroccan patients ( sometimes also other immigrant patients)

(ACTIZ, 2009) [22]

(Buiting et al., 2008) [35]

Immigrant patients' rates of death in hospitals was high. (59\% for immigrants vs $32 \%$ for Dutch)

(De Graaff and Francke, 2003a) [17]

(De Graaff and Francke,

2009) [45]

(De Graaff et al., 2010a) [18]

(Meulenkamp et al., 2010) [65]

(Koppenol et al., 2006) [59] -

(Korstanje, 2008) [60]

(NOOM, 2009) [23]
Relatives advised Dutch providers of home care and elderly care not to strive for standard culture-related care programs but for an individual approach. They asked for support in dealing with loss of independence of their patient and facilities to organize culture-specific rituals.

-

Asking for professional care is restricted by feelings of shame, not only personally (being vulnerable or naked) but also socially (adopting 'Dutch' care instead of clinging to own traditions).

Few Turks and Moroccans were referred to home care, especially those who did not speak Dutch.

According to GPs and nurses, main barrier to home care was communication problems.

The views of Turkish and Moroccan patients and relatives on 'good care' and ' good communication' were often different from views of Dutch care providers.

Elderly migrants were concerned about hygiene and body care; they wished to take a shower daily. Women preferred to be cared for by female care providers.

Professional care homes should have enough room for visitors and religious duties; professionals who can speak Turkish/Moroccan.

Many Turkish and Moroccan elderly didn't understand aetiology of illness, they feared cancer as contagious, and fatal. Patients asked for care in acute situations, but being unaware of diagnosis, they felt cured as soon as they felt a little better.

Even in hospital relatives felt responsible for wellbeing of patient, they were very alert to professionals' activities. Discharge from hospital was too abrupt, decisions were not sufficiently communicated.

Use of professional care was often impeded by the community (insisting on family care) and administrative procedures. 
Turkish and Moroccan men generally would like to have body hair shaven, but they didn't dare to ask care providers to help them. Bathing should be done with running water.

(VPTZ, 2008b) [26] (V)

(Yerden and Van Koutrike, 2007) [82]

\author{
Most Turkish and Moroccan patients \\ preferred to die at home, but being \\ in hospital was preferred if one still \\ hoped for cure, or wanted to unburden \\ the family.
}

Relatives did not ask for professional help, they wanted to stay in charge, and feared financial debts.

Relatives felt professional care didn't fit with traditions of hygiene, halal food, and help of people of same sex.
Forty studies addressed the experiences of Turkish subjects. Seven of these forty studies concerned immigrants with a Turkish background either living in Germany (one study), Belgium (one study) or the Netherlands (five studies). Of the 33 studies of Turkish people living in Turkey, five studies were performed in provinces in Eastern Turkey, but most concerned the situation in modern cities in Western or Central Turkey.

Four studies focused on Moroccans in Morocco and addressed the experiences of people living in Rabat and Casablanca, two large cities in Morocco with specialized cancer care.

Additionally, we found thirteen studies of Turkish and Moroccan immigrants in the Netherlands. Four of these thirteen studies focused on Turkish and Moroccan immigrants only, while the other nine presented data about several immigrant groups living in the Netherlands, including Moroccan and Turkish immigrants.

\section{Research questions and subjects}

Most research questions addressed the needs or attitudes of care users or care providers, the problems of care professionals or relatives, or factors influencing the access to or the quality of care.

Patient perspectives were described in 22 of the 57 studies, relatives were involved in 15 studies, physicians in 23 studies and nurses in 17 studies. Some studies combined the perspectives of patients and relatives, for example when relatives were asked to describe the views of their ill patients $[17,22,33]$. Some studies combined the perspectives of relatives and professionals $[23,26,59,66]$. Other studies compared the views of patients and relatives with the views of professionals $[18,45,48,69]$ or compared the views of physicians with the views of nurses $[40,75]$.

\section{Designs, sample sizes and instruments}

Many studies (35 of the 57) had a quantitative design, often using self-developed survey questionnaires. However, three studies [29,30,34] used existing instruments, namely the Hospital Anxiety and Depression Scale, the Barriers Questionnaire II (BQ-II) or the European
Organisation for Research and Treatment of Cancer Quality of Life Questionnaire.

Twenty studies had a qualitative design, generally using semi-structured interviews or focus groups. Two studies used a mixed design. Studies performed in Turkey and Morocco were often quantitative in nature, involving large samples: e.g. 150-1,000 Turkish professionals or 600-1,600 Moroccan patients. Sample sizes in studies performed among Turkish or Moroccan immigrants in Europe were often smaller (less than 20 research subjects), related to the fact that these studies often had a qualitative design (see Table 5). One exception is the study by VPTZ (Vrijwilligers Palliatieve Terminale Zorg Nederland=Volunteers for palliative care in the Netherlands) describing focus groups with a total of 255 Moroccan and Turkish relatives.

\section{Methodological quality}

As said, the methodological quality of all the selected publications was assessed by one reviewer and half of the publications by a second reviewer as well. Scores from the first reviewer varied between 12 and 36 with a mean of 25 (see the Methods section for the range). Those from the second reviewer ranged from 16 to 36 with a mean of 27.4. The Pearson correlation between the scores of the two reviewers was $0.75(\mathrm{p}<0.05)$. Cohen's kappa for the between the category scores was also significant $(\mathrm{p}<0.05)$.

The total score for each study is presented in Table 5 (the mean score is presented for studies assessed by both reviewers). Six studies fell in the 'low methodological quality' category, 32 in the 'moderate' category and 19 in the 'good quality' category. The aspects most frequently given a low score were 'background and clear statement of the research aims,' 'addressing ethical issues' and 'sampling strategy'. The six studies [23,28,37,52,60,74] with low scores did not show results that were fundamentally different or contradictory to the other results and are therefore not excluded or treated differently in the synthesis.

We felt that the findings from our study could best be presented by clustering them into four themes, namely 
Table 3 Findings relating to perspectives on end-of-life care and decision making

Perspectives regarding end-of-life decisions: euthanasia or hastening death / withdrawing or withholding life-prolonging treatments/ continuing to offer food and artificial nutrition

Involvement in end-of-life care or decision making

\begin{tabular}{ll}
\hline Study & Hope for cure \\
and faith in Allah
\end{tabular}

Findings concerning Turkish patients

(Akpinar et al.,

(Balseven Odabasi and -

Ornek Buken, 2009) [31]

(Beji et al., 2005) [32] After learning diagnosis $87 \%$ of patients with gynaecological cancer wanted survival and $50 \%$ recovery. If treatment should fail $75 \%$ would struggle, $27 \%$ would trust in God.
40\% of Turkish nurses found withdrawing life-prolonging treatments justified when no medical benefit; $81 \%$ preferred continuing treatment for a dying child (50\% until brain death), 19\% preferred palliative care. In case a baby would survive with physical or mental impairment $41 \%$ left decision to family, if progressive irreversible illness $65 \%$ found family should decide.

$68 \%$ agreed that artificial nutrition should always be continued.

Elderly patients accepted life-prolonging proposals of physicians. Even when patients wanted to die, relatives wanted them to live.

Abstaining from life-prolonging treatments only in patients suffering from bad family relations, pain or depression (37\%), 63\% wanted to survive. If treatment was to fail, $63 \%$ would ask for life prolongation $36.8 \%$ would refuse that.

(Celik et al., 2009) [38] -

(Cobanoglu and Algier, -

2004) [40]

(Cohen et al., 2006) [41] -

(Erer et al., 2008) [49]
Withdrawing or withholding life-prolonging treatments was problematic for $48 \%$ of physicians and $46 \%$ of nurses. Physicians found withdrawing more difficult than not initiating treatment. Nurses felt uncertainty in absence of written DNR orders.

Acceptance of euthanasia is low in Turkey. Weak religious belief is most closely associated with higher acceptance of euthanasia, as well asyoung age, being from non-manual social class, higher education, belief in national traditions and history.
Clinicians should accord a larger role to patients in end-of-life decisions. Discussing medical ethical issues openly is not easy in Turkey, leaving physicians alone in decision making.

Physicians need training to handle communication about reanimating or passive euthanasia.

$82 \%$ of nurses provided an environment suitable for family to say goodbye to deceased patient, $5 \%$ allowed family to help care for deceased patient. Nurses did not apply special cultural or spiritual activities.

$87 \%$ of cancer patients declared that knowing diagnosis is a patients' right; 92\% found physician should inform them about disease and choices of treatment, but $77 \%$ regarded it to be an obligation for physician to provide this information. 43\% agreed that patients could refuse treatment. $79 \%$ wanted to take part in decisions. 
Table 3 Findings relating to perspectives on end-of-life care and decision making (Continued)

(Ersoy and Gundogmus, -

2003) [54]

(Ilkilic, 2008) [56]

(lyilikci et al., 2004) [57] -

(Karadeniz et al.,

2008) [58]

(Kumas et al.,

2007) [61]

(Mayda et al,

2005) [62]
$84 \%$ of physicians would prolong life of a patient who had stated he did not want to live with aid of artificial respiration devices, but if his wife wanted him to live, only 13\% would respect patient's wishes.

In case of a relative who cannot live without mechanical support, Turkish parents wished to prolong life as long as possible, referring to religious duties. German physicians proposed stopping care when a situation is medically hopeless.

$58 \%$ of anaesthesiologists would continue prolonging treatment when family wanted cessation, $85 \%$ would continue life support when family wanted continuation, $68 \%$ would continue minimal support in case of no likelihood of recovery.

$28 \%$ of health professionals found life support should be decreased when patient wanted euthanasia, 35\% rejected this option. $27 \%$ agreed with statement that euthanasia should be legalized in all countries, $24 \%$ was undecided and $49 \%$ disagreed with this statement. $43 \%$ would not perform euthanasia if legalized. 42\% agreed with statement that a patient should decide on his right to live. 19\% was undecided and $41 \%$ disagreed with this statement. 11\% agreed with statement that if a patient wanted euthanasia, nutrition should be stopped, $14 \%$ was undecided, $75 \%$ disagreed with this statement.

$51 \%$ of ICU nurses stated they did not have enough knowledge about euthanasia.

$56 \%$ stated it was patient's right, $24 \%$ would support patient's request for active euthanasia, $39 \%$ would support passive euthanasia. 75\% opposed active euthanasia, $73 \%$ opposed passive euthanasia. 81\% thought legalization would be exploited, 77\% said it would be exploited for inheritance reasons. 40\% thought passive euthanasia is practiced in some cases, $20 \%$ that it is never practiced in Turkey.

$84 \%$ of oncologists agreed euthanasia should be discussed in Turkey. $42 \%$ believed euthanasia is performed in Turkey. 38\% advised incurable patients not to start therapy.

34\% had been asked for euthanasia. $44 \%$ did not object to euthanasia $56 \%$ objected to it as unethical.

$51 \%$ of oncologists had sometimes withdrawn treatment.
$66 \%$ of Turkish anaesthesiologists had given DNR orders, $14 \%$ discussed DNR with family, $1 \%$ with patient, $83 \%$ with colleagues and $2 \%$ with Ethics Committee. $10 \%$ preferred doctors to decide, $31 \%$ preferred to decide with patient, relatives and responsible physician, 58\% preferred consensus between hospital administrators, Ethics Committee patient, relatives and physician.

$54 \%$ of oncologists thought patients should decide about euthanasia, $42 \%$ said families and doctors, $4 \%$ relied on families.

$64 \%$ of those who performed euthanasia $(n=42)$ thought relatives and doctors should decide on withdrawing treatment in case of euthanasia.

$36 \%$ thought patients and doctors and patients should decide, $2 \%$ thought that only 
$(\mathrm{Oz}, 2001)[69]$

(Ozdogan et al. 2004) [71]

(Ozkara et al.,

2004) [73]

(Pelin and Arda,

2000) [74]

(Tepehan et al,

2009) [75]
$58 \%$ of nurses and physicians defined euthanasia as 'allowing death, leaving patients to die', 17\% as 'passive euthanasia, not active death determined by others', 13\% as 'painless peaceful death'.

$21 \%$ of nurses and $18 \%$ of physicians had requests 'to make death easy'. For $63 \%$ of nurses and $43 \%$ of physicians pain was major reason, but pain should be controlled.

For $14 \%$ of nurses and $30 \%$ of physicians loss of hope was major reason. Euthanasia seemed appropriate for $81 \%$ of nurses and $66 \%$ of physicians 'if there was no possible treatment or other alternative'. 13\% answered 'if patient is conscious and he and his family wanted it'.

$41 \%$ of nurses wanted an active role in euthanasia, $54 \%$ was undecided.

$66 \%$ of nurses and $61 \%$ of physicians would not do it after legalization.

$-$

92\% of physicians defined euthanasia a $s$ the performance of death upon request of a patient, who has a progressive, unbearable and fatal disease after a long and painful period with no hope of recovery in today's medicine, with assistance of a physician, in better conditions and without pain'.

$85 \%$ wished for a public debate. $61 \%$ did not approve of euthanasia. Arguments against euthanasia were: probable abuse (42\%), ethically incorrect (25\%), religious (19\%) en illegal (11\%).

$30 \%$ of physicians felt practicing euthanasia should be punished; $56 \%$ thought that euthanasia is practiced,

19\% had encountered a euthanasia request.

$62 \%$ of physicians supported euthanasia $60 \%$ only on conscious and persistent demands, 33\% under strict regulations, $32 \%$ only passive form. $39 \%$ did not support euthanasia, because doctors should save life (58\%) and science might solve problems (54\%).

Nurses and doctors did not have same knowledge about different forms of euthanasia (active, passive, physician-assisted suicide and involuntary euthanasia); most well known was passive euthanasia (73\% of doctors and $63 \%$ of nurses).

$56 \%$ of doctors and $53 \%$ of nurses wanted euthanasia to be legalized.

$57 \%$ of nurses and $59 \%$ of doctors thought it is performed secretly.
Many physicians favoured a paternalistic approach and felt that patients are not able to cope emotionally with bad news.

Keeping information away from patients in disease process especially in poor prognosis was almost a common practice in Turkey. 
(Turla et al., 2006) [76] -

(Yaguchi et al., 2005) [79]

ICU physicians in Turkey preferred oral DNRe orders, while $80 \%$ of Western physicians would apply written DNR orders.
$40 \%$ of ICU doctors discontinued treatment in patients with an incurable disease on more than one occasion.

In ICU higher scores. If legalized 28\% of ICU doctors would apply it versus $15 \%$ of paediatrics. $24 \%$ of ICU nurses would participate. Justifications for objecting to legalization were: not ethical, can be abused, religious beliefs and personal values. $65 \%$ of nurses and $73 \%$ of physicians agreed that individuals should have right to decide about own death.

Euthanasia is defined as the killing, through either an active or passive way, of someone who suffers from an illness which arouses pity and who will never get better when asked by either the person himself/herself or his/her relatives. $66 \%$ of health professionals thought euthanasia as such should not be performed.

They were all worried about abuse of euthanasia, 30\% noted religious reasons, 30\% found it unethical and $15 \%$ illegal.

8\% had been asked to perform euthanasia.

If it were legal in Turkey $74 \%$ would not perform it.

$81 \%$ found euthanasia can be misused if it is legal.

Withdrawing or withholding life-prolonging treatments: In case of patient in vegetative state, IC physicians in Turkey chose life prolonging more often than physicians in other countries.

They would, like their colleagues of southern Europe, treat complications with antibiotics, colleagues in northern and central Europe would actively withdraw therapy.

Findings regarding Moroccan patients

(McCarthy et al., 2004) [63]

(Errihani et al., 2005) [52]

$48 \%$ of cancer patients were active believers. Faith helps control fear and incertitude.

(Errihani et al 2006) [50]

After diagnosis of cancer 50\% of practicing Muslim patients felt culpable and 93\% started practicing. In both groups new behaviours: wearing of "hijab", eating plants recommended in de Koran.

(Errihani et al., 2008) [51]
Use of oxygen + sedation stopped after complications. Morphine was used only for terminally ill patients.
Those who don't actively practice their belief (49\%) felt guilty, while those who were practicing believed
$57 \%$ found it useful to have discussions about euthanasia.

63\% thought decision should be made by both physician and family. 
Table 3 Findings relating to perspectives on end-of-life care and decision making (Continued)

Allah was testing them,

so they accepted disease.

Findings regarding Turkish and Moroccan patients ( sometimes other immigrant patients as well)

would decide on end of life.

(Buiting et al., Physicians' data on treatment

Immigrants had fewer euthanasia requests

2008) [35]

of immigrant and Dutch patients:

.

were more often seen as incompetent

( $60 \%$ of immigrants vs $45 \%$ of Dutch),

more often physicians' decisions (39\% of immigrants vs $25 \%$ of Dutch).

less wish to hasten end ( $5 \%$ of immigrants vs $17 \%$ of Dutch).

(De Graaff and Francke, 2003a) [17]

(De Graaff and Francke, 2009) [45]

(De Graaff et al., 2010a) [18]

(Koppenol et al., 2006) [59]

(Korstanje, 2008) [60]

(Mostafa, 2009) [66]

(NOOM, 2009) [23]
Also less withholding of life-prolonging treatments for immigrants than for native Dutch (12\% vs. $15 \%)$; more withdrawing (20\% of immigrants vs $12 \%$ of Dutch), more respiration (38\% of immigrants vs $16 \%$ of Dutch), more cardiovascular medicines. (30\% of immigrants vs $11 \%$ of Dutch), but less artificial nutrition and hydration ( $12 \%$ of immigrants vs $28 \%$ of Dutch).

Main concerns about 'good care' at end of life expressed by Turkish and Moroccan families were: maximum treatment and curative care till end of lives, never having hope taken away, devoted care by families, avoiding shameful situations, dying with a clear mind and being buried in own country. These wishes often conflicted with values of Dutch professionals, like improving quality of life, giving sufficient pain and symptom relief.

'Good' care implied not stopping feeding.
Relatives noted that decision making within families was often difficult as it was not clear who had to decide on what topics.
Many Turkish and Moroccan patients wished to die in home country, but return is hampered when they have few relatives there and more relatives in Netherlands.

According to GPs and nurses, patients do not understand them. Non-satisfaction is often rooted in communication problems, Turkish and Moroccan patients need coaching by GP and nurses.

Relatives wished to decide as a family what information is given to patient. This wish sometimes conflicted with views of Dutch physicians.
Talking about cancer was not done in Turkish or Moroccan community.

Elderly and children believed that aged people deserved rest children had to look after them, 


\begin{tabular}{|c|c|c|c|}
\hline & & & $\begin{array}{l}\text { and decision making should be } \\
\text { left to children. }\end{array}$ \\
\hline \multirow[t]{4}{*}{$\begin{array}{l}\text { (Van Wijmen et al., } \\
\text { 2010) [78] }\end{array}$} & \multirow[t]{4}{*}{-} & \multirow[t]{4}{*}{-} & $\begin{array}{l}\text { Significantly less use of ADs } \\
\text { among people who had: }\end{array}$ \\
\hline & & & $\begin{array}{l}\text { - children and a good relation } \\
\text { with them, (15\% versus } 8 \%) \text {, }\end{array}$ \\
\hline & & & $\begin{array}{l}\text { - only elementary or basic } \\
\text { vocational training ( } 24 \% \text { versus } \\
12 \% \text { and } 8 \% \text { for those with } \\
\text { secondary school and higher), }\end{array}$ \\
\hline & & & $\begin{array}{l}\text { - a religious belief (16\% versus } \\
\text { 10\%). }\end{array}$ \\
\hline \multirow[t]{2}{*}{ (VPTZ, 2008b) [26] } & \multirow[t]{2}{*}{$\begin{array}{l}\text { Reciting Koran verses } \\
\text { gave peace to many } \\
\text { Muslims. Dutch care } \\
\text { professionals were not } \\
\text { involved in rituals. }\end{array}$} & \multirow[t]{2}{*}{ - } & $\begin{array}{l}\text { In last days many people were } \\
\text { assisting in practical matters, but } \\
\text { personal care was often done by } \\
\text { one or two women only. }\end{array}$ \\
\hline & & & $\begin{array}{l}\text { Islamic women were often not } \\
\text { involved in funeral. }\end{array}$ \\
\hline
\end{tabular}

the experiences and perceptions regarding family care, those regarding professional care, those regarding end-of life care and decision making, and finally the experiences and perceptions regarding communication in end-of-life care.

\section{Findings related to perspectives regarding family care}

Seventeen studies addressed the contribution of family members in the care for incurable Turkish or Moroccan patients. Three topics were mentioned frequently: family care is seen as (1) a social duty, (2) an economic necessity, and (3) a burden.

\section{Family care as a duty}

All studies - whether they were performed in the countries of origin or in the host immigrant countries - indicate that family members are key care providers. For example, it was shown by studies conducted in Turkey that family care is a duty [28], and that Turkish patients are mainly cared for by the family [68]. In addition, studies performed in Morocco showed that most patients (92\%) were supported by the family [50,52]. Studies performed in the Netherlands also stress that Turkish and/ or Moroccan patients and their relatives consider family care as an obvious duty $[17,55,80,81]$. Many patients expected their children and their children's partners to take care of them. In practice daughters or daughters-inlaw did most of the work $[17,55,81,82]$. Family care involved activities like preparing food all through the day for the patient and for the many visitors, doing the paperwork, accompanying the patient to the doctor as an interpreter and providing personal care $[55,65,81]$.

\section{Family care as an economic necessity}

Some studies - performed in the home countries noted that the emphasis on family care is also the result of poverty. In Turkey, families' poverty and hospitals' lack of resources were seen as problem by physicians [40]. In Morocco, cancer patients said that professional treatment was frequently compromised by poverty and lack of medical insurance [50,52]. Often families had insufficient monthly income to pay for professional medical treatment.

\section{Family care as a burden}

Family care is considered burdensome - especially in the Dutch studies. Studies conducted among Turkish families living in the Netherlands indicated that sometimes sons and daughters of Turkish patients decided to move out in order to flee from the duty they saw as too heavy [80]. One reason for relatives' exhaustion was the contrasting opinions of patients and relatives regarding the feasibility of family care $[17,81]$. Other studies found that relatives felt that the illness imposed a heavy financial burden on the family, as the health-care insurance did not cover all the costs of family care $[26,60,77]$.

\section{Findings relating to perspectives regarding professional care}

Twenty-five studies addressed the contribution of professionals in the care for incurably ill Turkish and Moroccan patients. Three topics were mentioned frequently: (1) a preference for hospital care, (2) barriers to professional care and (3) the quality of professional care. 
Table 4 Findings relating to perspectives on communication

Study

Communication about

Communication about pain,

Language barriers

Communication

within

family and within

community

Findings concerning Turkish patients

(Aksoy, 2005) [28]

$61 \%$ of general public and

$89 \%$ of professionals wanted

to know diagnosis, but 58\%

of general public and $71 \%$ of

professionals preferred to hide

it from relatives.

(Atesci et al., 2004) [29]

$55 \%$ of cancer patients were unaware of diagnosis, $45 \%$

were aware; $68 \%$ guessed it

from treatment process:

$15 \%$ had been fully informed.

(Bagcivan et al., 2009) [30]

(Balseven Odabasi and

Ornek Buken, 2009) [31]

(Betke, 2005) [33]

(Bozcuk et al., 2002) [34]
$85 \%$ of patients found that if a patient is diagnosed with cancer he should be informed about diagnosis.

$68 \%$ of physicians arqued they

had to tell diagnosis first

to patients before informing

relatives.

Turkish elderly preferred not to talk about cancer or any other negative diagnosis to very ill patient. They didn't want to reveal diagnosis to an

incurable patient and preferred doctors to tell truth only to

relatives.

$44 \%$ of cancer patients not aware of diagnosis.

$44 \%$ of cancer patients informed about diagnosis.

There was no significant

difference between scores on

quality of life (QLQ-C30)

between patients who knew

and patients who did not

know diagnosis.
More psychiatric disorder in patients

aware of diagnosis. Physicians may

be reluctant to reveal diagnosis

and prognosis, as cancer is

regarded as a death sentence.

Many patients did not want to talk

about pain as they feared

dependency on analgesics and

did not want to upset relatives.
Predictors of good emotional

functioning:

gender (males were

more often

accompanied) and social functioning. 
Table 4 Findings relating to perspectives on communication (Continued)

(Buken, 2003) [37] 63\% of patients diagnosed with

cancer not aware of diagnosis.

Level of informing increased

with chance of recovery

and patients' socio-economic

and educational level. 52\%

of physicians were 'protective'

preferred not to tell truth.

Reasons for not informing: lack

of legal foundation and control

and difficulty of changing

(Cetingoz et al., 2002) [39]

protective physicians' attitude.

$75 \%$ of the general Turkish

population had satisfactory

knowledge of cancer, 13\%

thought cancer is contagious,

$87 \%$ thought cancer is fatal

but $40 \%$ also believ is fatal,

but $40 \%$ also believed that
half of all cancers can be cured.

half of all cancers can be cured.

cancer diagnosis, but only $63 \%$

wanted relatives to be informed.

Presence of cancer in a relative did

not influence results.

(De Meyere, 2004) [47]

Less educated patients

sometimes got to false

information and believed that

cancer is contagious.

(Demirsoy et al.,

2008) [48]

$16 \%$ of patients (mixed cancer and

non-cancer patients) were not aware

of diagnosis; $84 \%$ knew diagnosis,

but $19 \%$ of these reported a

different diagnosis than on chart.

$66 \%$ of patients wanted to be

informed about diagnosis, 33\% did

not want this, $95 \%$ wanted to know

effects of available treatments.

$90 \%$ of nurses wanted to inform

patients about diagnosis and

prognosis, $75 \%$ reported that

patients should be informed.

(Erer et al., 2008) [49]

$87 \%$ of patients (more types of

cancers, 38\% breast cancer) agreed

that patients had right to be

informed about diagnosis.

(Ersoy and Goz, 2001) [53]

$76 \%$ of nurses would in case a breast

cancer patient asked for her 
(Groen-van de Ven and Smits, 2009) [55]

(Ilkilic, 2008) [56]

(Meric and Elcioglu,

2004) [64]

(Oflaz et al., 2010) [67]

(Oksuzoglu et al.,

2006) [68] diagnosis, tell truth (some after

consulting physician):

$53 \%$ of physicians would reveal

diagnosis to a HIV patient, $8 \%$ would

tell family but not patient, $18 \%$

would tell it to patient and his family

together.

$44 \%$ of physicians would tell patient

his diagnosis of lung cancer, 19\%

would first investigate patients'

competence, $12 \%$ would ask consent

of family, $16 \%$ would not tell patient

in order not to harm him.

The Christian Turks in this study

obviously cared for parents,

encouraged by faith and by

community. Professional care could

only be accepted when a trustf

relation with relatives had been

created.

$57 \%$ of nurses noted that patients

were not informed about diagnosis and prognosis.

$58 \%$ thought patients should not be informed about prognosis.

All nurses felt relatives should be

informed, 66\% wanted to inform

when diagnosis is clear, $34 \%$ wanted

to inform when problems arise.

$96 \%$ of nurses did not want to

inform patient about his termina

status.

$60 \%$ did not think a person should

be told his illness is incurable or

terminal.

$48 \%$ of relatives wanted patient to

be informed; $39 \%$ thought diagnosis
$29 \%$ of nurses faced problems in communication about care for terminally ill patients, they had feelings of empathy and loss when people die, $7 \%$ saw no problems and 63\% had problems with some 'special' patients.
Language barriers impeded physicians in making joint decisions with Turkish patients. They often could not understand discussions of patients and interfering

relatives. 
Table 4 Findings relating to perspectives on communication (Continued)

(Ozcakir et al., 2008) [70]

(Ozdogan et al., 2004) [71]

(Ozdogan et al., 2006) [72]

(Pelin and Arda, 2000) [74]

(Van den Bosch, 2010) [77]

(Yerden, 2000) [80] should not be disclosed, $13 \%$ was

hesitant.

$87 \%$ wanted family to be informed,

$80 \%$ of the $39 \%$ that did not want to

inform patient, wanted only family

to be informed.

$89 \%$ thought treating doctor should be messenger.

Medical students found talking to patients important, patients should get permission to die at home.

Students disagreed that incurably ill

patients should be told diagnosis.

$66 \%$ of relatives did not want patient to be informed about diagnosis; $57 \%$ because patient would be upset,

$29 \%$ because patient would not

want to know it.

The percentages that never, rarely, generally, and always told truth

about diagnosis were 9\%, 39\%, 45\% and $7 \%$.

$54 \%$ of physicians felt influenced by requests from relatives, $46 \%$ not.

Physicians who felt influenced told truth less often than those who did not. Training in breaking bad news resulted in higher scores of telling truth

93\% of physicians thought patients should be informed about diagnosis, but one should avoid talking about life expectancy. 30\% said they may choose to inform relatives.

Older and more experienced physicians gave more information

Many Turkish patients generally

trusted medical competence of GP,

but communication was limited as

Turkish elderly did not accept idea of incurability and felt discriminated or not being taken seriously. Some

thought GP was not informing them

fully.
Many Turkish patients did not want to

talk about psychological problems. 
Findings regarding Moroccan patients

(Errihani et al., 2005) [52]

(Errihani et al., 2006) [50]

(McCarthy et al., 2004) [63]

Physicians and nurses believed that pain in children with cancer is rarely expressed in Morocco, which hampered assessment of pain. For some Moroccans pain was inevitable. Some feared morphine addiction.
$33 \%$ of patients (diagnosed with cancer) were not aware of diagnosis and prognosis.

In 89\% of cases relatives were informed, in $9 \%$ only some very close kin, in $2 \%$ of cases patien lived with their disease in full

$1 \%$ of patients' families thought that cancer is contagious.
Iliteracy and insufficient knowledge of Arabic caused problems. 37\% were illiterate and $25 \%$ spoke Berber only. from relatives or members of difficult to distinguish patients' wishes apart from relatives' wishes, especially when

In cases with language barriers with relatives who were acting Dutch professionals wished to inform patient and to realize Turkish and Moroccan relatives wished to keep patients' hope alive.

Turkish and Moroccan patients

disliked direct way in which Dutch

care providers informed patients.
Important information came community who worked in health sector.

GPs and nurses found it relatives were translating. Dutch professionals struggled as interpreter and as person in charge.

Informing within community is hampered by fear of gossiping.

GPs and nurses didn't recognize influence of local migrant community on decision making in

Relatives needed information about diseases and choices of treatments, they lacked role models in care for dying patients. 
(Koppenol et al., 2006) [59]

Relatives impeded doctors in

informing patient about cancer

women were often breast cance

because of surgery decisions. Many

patients were in need of information

they felt bad, wanted to know

reasons for complaints.

(Korstanje, 2008) [60]

(Mostafa, 2009) [66]

(NOOM, 2009) [23]

Patients and relatives disliked direct

way Dutch care providers informed

patients about diagnosis.

First generation immigrants did not talk about life-threatening illnesses. They were not amused by Dutch

doctors informing them about

diagnosis with little respect for

family relations. Second generation

immigrants wanted to be informed. financial management. Some were illiterate; others did not

have enough mastery of

Dutch language.

Relatives didn't contact professionals because of language problems. Nurses were not well-informed as they spoke with

Dutch-speaking relatives, who were not primary carers.

Most women (with breast cancer) felt GP did not listen, resulting in late diagnosis. Women wanted treatment for physical complaints, not for menta

Many immigrants didn't talk about mental problems, instead they

mentioned headache, pain in back or belly. Alzheimer disease was not recognized.

Assessment of symptoms was hampered by language barriers, as patients lost knowledge of Dutch. activities, but they

also fear gossiping of

compatriots.

Some patients didn't want other people to be informed about illness; they feared gossiping and social isolation.

Caring relatives often felt overburdened but could not discuss it, since helping was obviously expected.

Elderly faced language barriers, so children did administration.
Parents and children created a dilemma: ideal of children taking care of parents prevented them from discussing openly and looking for real solutions.

Relatives who cared for dying patients advised discussing illness and dying Turkish communities. within Moroccan and 
Table 5 Methodological characteristics of the studies included

Reference, language/ Research question*
country [nr]

Research subjects

Design

Data collection

(variables/topics

Meth.

Studies concerning Turkish patients

Akpinar et al., 2009,

English/Turkey [27]

What are intensive care nurses'

attitudes to end-of-life decisions?

What are reasons for limited use of

Aksoy, 2005,

English/Turkey [28]

hospice facilities in Turkey?

Atesci et al., 2004,

English/Turkey [29]

Bagcivan et al., 2009,

English/Turkey [30]

Balseven Odabasi and

Ornek Buken, 2009,

Turkish/Turkey [31]
How is awareness of cancer diagnosis related to presence of psychiatric morbidity?

What are barriers to pain management of cancer patients? What factors population? determine barriers in Turkish
54 nurses at a Paedriatric Intensive Care

Nursing Symposium and 101 nurses at

a Congress on Intensive Care Nursing.

200 volunteers, half of them were nurses or physicians in Ankara, Izmir Sanliurfa or Erzurum.

\section{7 patients having chemotherapy in different departments.}

Quantitative study using questionnaires

Self-administered

questionnaire on personal

and professional

characteristics, attitudes

to end of life and

futile treatment.

Quantitative study using questionnaires

Self-administered

questionnaire

on preferences for

staying in hospital or at

home, for sending relatives

to hospital or letting them

stay at home, for

knowing diagnosis and

letting relatives know their

diagnosis, and experiences

with courses on terminal

care.

Quantitative study using questionnaires

and assessment by a

psychiatrist

Hospital Anxiety

and Depression Scale,

General Health

Questionnaire. Psychiatric

diagnosis (DSM-IV)

Added questions: What

do you think you are

suffering from? And

Why do you think you

are in hospital?

Quantitative study using BQ-II measures about

beliefs concerning fear of

addiction, fatalism, anxiety,

not complaining, treatment,

side-effects, immune system,

analgesics masking

symptoms. Some items

were added from

Brief Pain Inventory and

from Pain Management

Index.

Quantitative study using Questionnaire and

questionnaires vignettes developed

and use of vignettes

by Ruhnke et al. (2000)

addressing whether

patients should be

informed about an in Turkey in diverse clinical

influence of patients

physicians and family

members on decisions?
University Hospital in 2007-2008

pediatricians, anesthetists, internists).
25.5 
Beji et al., 2005,

English/Turkey [32]

Betke, 2005,

Dutch/Netherlands [33]

English/Turkey [34]

Buken, 2003,

English/Turkey [37]

Celik et al., 2009

English/Turkey [38]

Cetingoz et al., 2002,

English/Turkey [39]
What are reactions of gynaecologic cancer patients to poor prognosis and what are their preferences

regarding location of terminal care

and life-sustaining technology?

What are specific needs of Turkish elderly regarding palliative care

and how can Dutch nursing

homes fulfil these needs?

What is current truth-telling practice for cancer patients in Turkey and

does disclosure of truth affect quality

of life?

How can physicians give bad news

to a terminally ill patient in

an appropriate manner?

What does a nurse do to care

for deceased patients in ICU?

What factors influence this care?

What is basic knowledge of and general attitudes about cancer?
68 patients visiting

gynaecologic-oncology

policlinic of Istanbul University.

ualitative study using

semi-structured

interviews

Interviews: 10 Dutch and 2 Turkish

informants, (nurses, physicians and

others). Focus groups: 32 Turkish

elderly who were not ill yet.

100 cancer patients: 29 lung cancer

23 breast cancer 5 colon cancer, 6 gastric

cancer, 10 head and neck cancer, 26 other cancers.

Questionnaire for 58 physicians and 150 medical students. Interviews with $\mathbf{8 2}$ newly diagnosed cancer patients about different services.

29 nurses working in cardiovascular urgical ICUs.

630 subjects, none was known to have cancer (general public)

Qualitative study using

semi-structured

Mixed-method design

combining

questionnaires with

interviews

Mixed method

design using

questionnaires

and interviews

study questionnaires incurable cancer and

whether a

terminally ill patient wishing

to die should be

ventilated.

Self-administered topic list

on concerns and

reactions to diag

desires for location of

terminal care and

preferences for withdrawing

or withholding life-sustaining

technologies.

Topics addressed in

interviews and focus group

were: experiences

with delivered care,

information needs,

wishes regarding

accommodation, food and

staff.

Interviews: items on family

support. Questionnaire:

EORTC QLQ-C-30

measuring five

functional, nine

symptom scales and global

health status.

Questionnaire and interviews

about attitude of

Turkish physicians,

interferences

with truth telling

and regulations

on information giving

and patients

rights.

Qualitative observational

Observations concerned

nursing interventions for

patient and emotional

support for patients' relatives.

Quantitative study using

Self-administered

questionnaire on knowledge

about cancer (e.g. signs,

symptoms, preventive

measures, treatment

modalities) and on attitude 
Cohen et al., 2006, English/Turkey [41]

de Meyere, 2004

Dutch/Belgium [47]

Demirsoy et al., 2008, English/Turkey [48]

Erer et al., 2008,

English/Turkey [49]

Ersoy and Goz, 2001,

English/Turkey [52]

Ersoy and Gundogmus, 2003, English/Turkey [54]

Groen-Van de Ven and

Smits, 2009, Dutch

Netherlands [55]
What are perceptions of physicians compared with perceptions of nurses on ethical problems in ICU?

s terminating life of incurably ill accepted in 33 European countries? What are associations with acceptance of euthanasia and social and religious factors?

How do Turkish women in

Belgium deal with breast cancer?

What are nurses' and patients' attitudes regarding information sharing about medical diagnosis and prognosis?

What are views and expectations of cancer patients

regarding information and autonomy?

Can nurses recognize ethical problems and how do they

use ethical principles in decisions?

Can physicians recognize ethical problems and how do they use ethical principles in decisions?

What are experiences of family members of Suryoye elderly patients?
Data of European Values Study of

1999-2000 including 1206

respondents in Turkey (general public).

1 Moroccan, 3 Turkish and 7 Flemish informants (physician, nurses and others).

166 nurses and 435 patients.

165 nurses working at bedside

encountering real ethical problems.

207 physicians working in a hospita

\section{Relatives.}

(e.g. desire to know diagnosis,

to change lifestyles).

Quantitative study using questionnaires

Qualitative study using focus groups

Analysis of quantitative questionnaire

data

Qualitative study using semi structured interviews

Quantitative study using questionnaires

Focus group topics concerned end-of-life decisions,

communication, hierarchica

and social problems.

More specified categories

were euthanasia, futile

treatment, DNR decisions,

autonomy as parts of

end-of-life decisions.

European Values Study regards 34

more than 300 items,

e.g. one regarding acceptance

of euthanasia.

Interview topics were socia

medical and psychological

problems around breast

cancer.

Self-administered

questionnaire on informing

patients with a limited

life expectancy about

diagnosis and prognosis,

preserving hope and family

support in informing patients.

Self-administered

questionnaire on patients

rights regarding being

informed and autonomy.

Quantitative study using

questionnaires

Questionnaire on

cases involving nursing

care and

ethical principles (autonomy,

veracity, beneficence

or justice).

Quantitative study using

Questionnaire addressing

cases of physicians

involving care and ethical

principles (autonomy,

non-maleficence, beneficence or justice)

Qualitative study using

semi-structured

Topics were care history,

experiences of giving care,

personal caring qualities, 
lyilikci et al., 2004,

English/Turkey [57]

Karadeniz et al., 2008,

English/Turkey [58]

Kumas et al., 2007,

English/Turkey [61]

Mayda et al., 2005,

English/Turkey [61]

Meric and Elcioglu,

2004, Turkish/Turkey [64]
3 cases of dying patients. ercultural end-of-life

care? What concepts and

instruments can help

German doctors and Turkish

families to solve them?

What are practices of

Turkish anesthesiologists with

regard to withholding and

withdrawing of life support

from critically ill?

What are attitudes of

health professionals

towards euthanasia?

What are opinions about euthanasia of nurses who

work in intensive care units?

What is attitude of oncologists towards euthanasia in Turkey?

What problems face nurse in de communication with terminally ill patients?

369 anesthesiologists.

332 nurses, 91 midwifes.

186 nurses of 3 hospitals.

scientific meeting. religion and gender.

Qualitative design using case studies

Examination of

thoughts about euthanasia,

brain death, life prolonging

measures, right to know your

diagnoses, right not to know

it, hierarchies in

decision-making positions

within family and

potentials and limitations

of living wills.

Quantitative study using

Self-administered

questionnaire on education

religion, ICU facilities,

bed capacity, ICU experience,

experience with euthanasia,

DNR orders and DNR

decisions, and knowledge of

urkish Penal Code.

510 health staff, viz. 309 physicians,

Quantitative study using

questionnaires

Questionnaire based

on Euthanasia Attitude

Scale: items on status of

brain-dead persons,

life-extending technology,

ethics and legal issues.

Quantitative study using

Self-administered

questionnaire on nurses'

knowledge about euthanasia,

their definitions, their sources

of information, euthanasia

practices.

85 oncologists participating in a

Quantitative study using questionnaires

Self-administered

questionnaire on physician's approach to euthanasia, legal basis, euthanasia requests, actions towards passive

euthanasia and expectations.

125 nurses working on different

disciplines/wards with $<10$, with

$11-50$ and $>50$ dying patients per year.
Quantitative study using questionnaires
Self-administered

questionnaire on informing

patients and relatives about

prognosis, talking near

unconscious patients,

participation of psychiatrist

and physiotherapists in

palliative care team, feelings of

attachment, empathy and loss 
Oz, 2001, English/ Turkey [69]

Oksuzoglu et al, 2006,

English/Turkey [68]

English/Turkey [70]

Ozdogan et al., 2004,
English/Turkey [71]

Ozdogan et al., 2006,

English/Turkey [72]
What are concerns of nurses who care for oncology

patients and how are these

concerns related to their

working experiences?

What are attitudes and

opinions of people

accompanying cancer

patients regarding cancer

diagnosis disclosure?

What are views on euthanasia

of nurses and physicians

working at a hospital in Ankara?

113 nurses and 84 physicians.

270 relatives of patients visiting

outpatient unit for chemotherapy.

Quantitative study using

questionnaires

Quantitative study using questionnaires

253 first-year medical students of 2004-2005.

opinions of medical students

about doctor-patient communication

in case of dying patients and

patients with chronic diseases?

What are relatives' attitudes towards informing cancer patients about their diagnosis? What factors affect

this attitude?

What are self-reported truth-telling practices of physicians and what factors influence these in Turkey?

Quantitative study using

Relatives of 150 patients visiting outpatient unit. questionnaires

31 physicians participating

in $15^{\text {th }}$ National Oncology Meeting

Quantitative study using and recommendations to

improve care.

Questionnaire is an adaption

of list of feelings in Durham

\& Weiss (1997) on concerns

for dying patients. Added

tems on care for terminally

ill patients and pain treatment

and management.

Self-administered

questionnaire on telling

patient and relatives about

cancer diagnosis, on timing

of telling truth and

from whom it should

be learned.

questionnaire on definition

of euthanasia, views on

for whom it may

be appropriate, methods,

conditions, kinds of help and

information, feelings towards

patients requesting euthanasia,

responsibilities, willingness to

take a role now or when it

becomes legal.

Quantitative study using

Self-administered

questionnaire on experiences

in caring for someone with a

serious disease and doctor-

patient communication in case

of patients with chronic

diseases or dying patients.

Quantitative study using

Self-administered

questionnaire on attitude

towards informing patients

with cancer, religious beliefs,

daily activities, preference

about disclosure, previous

requests for information and

previous knowledge about

Self-administered

questionnaire on attitude

owards informing patients,

views on patients' mood,
3 
Tepehan et al., 2009 English/Turkey [74]

Turla et al., 2006,

English/Turkey [76]

Van den Bosch, 2010

Dutch/Netherlands [77]

Yaguchi et al., 2005,

English/Turkey [79]

Yerden, 2000, Dutch/

Netherlands [80]
Do physicians approve of egalization of euthanasia and assisted suicide? Is this

correlated to their specialties,

sex and workplace?

What are ethical attitudes of

physicians in Ankara in 1995-1996?

524 physicians.

\section{5 physicians and 206 nurses}

Has working in ICUs

an impact on attitude to

euthanasia?

What are attitudes of

health professionals

towards euthanasia?

What is the quality of life

of Turkish-Dutch elderly?

What are experience

influence confidence in GPs?

What are end-of-life attitudes of ICU physicians?

What are mutual expectations

of Turkish elderly and their

children with regard to traditional

care? What care is given and

what were consequences within

family?

545 professionals working a

health clinics and hospitals.

Interviews: 17 Turkish elderly.

Intensive care and Emergency

Medicine in Brussels.

\section{8 elderly and 32 relatives of}

knowledge, wishes to be

formed about diagnosis.

Quantitative study using questionnaires

questionnaire on definitions of

euthanasia, legal aspects of

euthanasia, expectations about

euthanasia and attitud

towards euthanasia.

Self-administered

questionnaire on attitudes.

e.g. towards informing

patients about disease process

and poor prognosis, alternative

medicine, euthanasia.

Self-administered working in internal medicine,
surgery and pediatrics in 3 hospitals.

using questionnaires

questionnaire on definition of

euthanasia, attitude

to euthanasia, number

of euthanasia requests and

experiences and expectations

about euthanasia.

Quantitative study

using questionnaires

Self-administered

questionnaire on definitions,

legal status and ways

of performing euthanasia,

euthanasia requests, attitudes

and expectations about

euthanasia.

Mixed-methods

study combining

interviews with

questionnaire

opics in interviews and-self

administered questionnaire

concerned exper

ageing communicating with

$\mathrm{GP}$, use of professional care

and health condition.

1961 ICU physicians, all participants

Quantitative study

of International Symposium on

using questionnaires

Self-administered

questionnaire on treatment

use of do-not-resuscitate

orders, strategy on mechanica

ventilation and use of

morphine in a constructed

15 families: 10 active elderly, 8 in

Qualitative study

using semi-structured

nterview topics concerned

migration experiences,

education and work, social

relations in Netherlands and

in Turkey, living cond

care of parents by childien

professional care. 
Table 5 Methodological characteristics of the studies included (Continued)

Yerden, 2004, Dutch/

Netherlands [81]

What housing conditions can

help care-dependent bedridden

family members in combining

family care with professional care?

Yildrim et al., 2009,

English/Turkey [83]

What is level of hopelessness

among Turkish patients with

cancer? How is this

anxiety and disease-related factors?

95 patients.

16 elderly patients, 11 partners

and 28 children/grandchildren

bedridden, 3 living in nursing home.

Qualitative study using

semi- structured interviews

Interview topics concerned

care needs and expectations,

caring tasks, social networks,

contacts between parents and

children, contacts with

neighbours, use of professiona

care, housing conditions,

knowledge and use of

modifications in the home and

wishes about housing.

Quantitative study using questionnaires

Questionnaire based on

questions of Pain Numeric

Rating Scale, Beck

Hopelessness Scale and

Hospital Anxiety and

Depression Scale.

14 nurses and 11 physicians

caring for children with cancer.

pain management among

health professionals caring

for children with cancer in

and contextual influences

for pain management?

Errihani et al., 2005,

French/Morocco [52]

What are psycho-social

characteristics of patients

treated in Cancer Institute?

Errihani et al., 2006,

English/Morocco [50]

What are psycho-socia

features of Moroccan

breast-cancer women?

Errihani et al., 2008,

English/Morocco [51]

What is impact of cancer

on Moroccan patients of

Moslim faith?
000 patients with a histological

confirmed cancer.

600 female patients with

histological confirmed breast cancer.

1600 patients.

antitative study

using questionnaires

Qualitative study

using interviews, f

ocus groups and literature
44 nursing professionals and relatives.
Topics in the focus

groups concerned pain

assessment and management,

training and resources, cultura

influences and beliefs about

pain management, need for

assessment and treatment

cancer-related pain in pediatric

oncology

\section{Qualf-administered}

questionnaire on identity and

questionnaire on identity and

origin, cultural and economic

position and effects of illness

on patient and family.

Self-administered

questionnaire on repercussion

of disease on patient and

family.

Self-administered

questionnaire focusing on the

repercussions of the disease

on religious belief and

practices.

Topics were accessibility

of formal care provisions

acceptance of discussing

diseases, contact with family

members, translation

problems, religion and
ACTIZ, 2009, Dutch/

in home care and

elderly care organizations? 
Buiting et al., 2008;
Buiting et al., 2009,

English/Netherlands [35,36]

De Graaff, 2002; De Graaff et al. 2005; de Graaff and Francke, 2003a; De Graaff and Francke, 2003b, English/Netherlands [17,42-44]

De Graaff et al., 2005

De Graaff and Francke,

2009, English/Netherlands [44,45]

De Graaff et al. 2010a,

English/Netherlands $[18,46]$

Koppenol et al., 2006,

Dutch/Netherlands [59]
Are frequency and

characteristics of end-of-life

practices of non-Western

migrants different from Dutch

natives?

What experiences do

Turkish and Moroccan

families of terminally ill

patients have of Dutch

home care in termina

phase? What factors

influence the access to

and use of home care in

the terminal phase?

What experiences do GPs

and home care nurses have

with regard to home care

for terminally ill Turkish

and Moroccan migrants

in the Netherlands?

What factors influence

their access to and use of home care?

What do cancer patients with

a Turkish or Moroccan

background mean by 'good

palliative care? How do

Dutch care providers deal

with ideas that diverge from

their own ideas about palliative

care?

What are perceptions of

immigrant cancer patients

on behavioural patterns,

communication with care

providers and use of health

care?

\section{2 physicians who signed}

death certificate for a non-sudden death.

Relatives of 9 Turkish and

10 Moroccan terminally ill patients.

88 GPs and 93 nurses, who had cared for terminally ill Turkish

and Moroccan patients.

6 patients, 30 relatives, 17 GPs 19 nurses, 5 specialists, 4 social workers and 2 pastoral workers, involved in palliative care for

19 Moroccan and 14 Turkish cancer patients.

Focus groups: Turkish, Moroccan, Surinamese and Caribbean health advisors. traditions, special care wishes and care provision.

Self-administered

en withholding

and withdrawing medical

reatments, alleviation of pain

or other symptoms or

prescription of drugs taking

into account or with explicit

intention of hastening death.

Qualitative study

using semi-structured

interviews

Topics were the health

situation of the patient in his

last half year, how family care

and eventually home care was

organized, the care process

felt needs and how these

needs were met.

Quantitative study

using questionnaires

Self-administered

questionnaire on care for their

last terminally ill patient, these

patients' needs and barriers to

use of home care, their care

giving and cooperation with

other professionals.

Qualitative study

Topics were decisions made

on care and treatment in

palliative stage, an evaluation

of these decisions and one's

own view on communication

in process.

Qualitative study

using focus groups
Keywords concerned disease,

immigrant groups, heath

attitudes, communication, and

health care utilization Topics

health care utilization. Topics

were cultural and religiour

aspects, social aspects,

knowledge, personal emotions,

informing patient of diagnosis

and prognosis, informational

needs, communication with

care providers, use of

treatments and care,

psychosocial support. 
Table 5 Methodological characteristics of the studies included (Continued)

Korstanje, 2008,

Dutch/Netherlands [60]
What are needs and experiences

of family members of

immigrant patients in a Dutch

hospital?

Meulenkamp et al.

2010, Dutch/Netherlands [65]

Mostafa, 2009,

Dutch/Netherlands [66]

NOOM, 2009,

Dutch/ Netherlands [23]

Van Wijmen et al., 2010,

English/Netherlands [78]

VPTZ, 2008a; VPTZ, 2008b,

Dutch/Netherlands $[25,26]$

Yerden and Van Koutrike,

2007, Dutch/ Netherlands [82]
What are wishes of elderly immigrants and what support do they need to achieve quality of life?

What are experiences of

immigrant women with breast cancer and what do they expect of their GP?

What is known among active vulnerability of elder immigrants in Netherlands?

To what extent Dutch people know of existence of advance directives (ADs)? Which people do draw up an $A D$ and for what reasons?

What are concerns of immigrants when caring for terminally ill?

What care is given by family members in immigrant families? senior immigrants about
7 relatives of Turkish, Moroccan and

West African Moslim immigrant patients.

interviews

informal care, intercultural

care, immigrants, nursing

hospital. Topics were hygiene,

religion, supporting patient,

discharge from hospital,

communication and becoming overburdened

83 elderly immigrants or their relatives, including 14 Turks and 12 Moroccans.

Qualitative study using interviews

Interviews with 3 Afghan, 2 Moroccan,

2 Turkish and 1 Iranian patients and

focus groups with patients and

professionals (e.g. nurses, physicians).

3 focus groups with elderly immigrants

+ Interviews with key informants.

\section{2 participants of a nationa}

panel of consumers of

health services, representative of

Dutch population (also involving immigrants).

Quantitative study using

questionnaires

Qualitative study using

interviews

and focus groups

Qualitative study using

focus groups

and interviews

\section{Moroccan relatives in}

Rotterdam and 115 Turkish relatives

in Enschede.

Qualitative study using

focus groups

49 relatives (17 Turkish)

Topics on physical welfare and health, living conditions, social participation and mental welfare.

Topics were: translation problems, communication, roles in care giving, cultura views, religion and personal experiences.

Topics were body and mind, social relations, materia conditions, work and productive life, values and inspiration.

Questions concerned ADs and 29 end-of-life issues, such as reasons for possession of ADs, awareness of ADs, preferences, experiences and expectations concerning dying, end-of-life care, decision making and quality of life.

Topics were views on 'good care', best place to die, preferences on who is caring, allocation of tasks in family and in professionals etcetera.

Qualitative study using Topics were social networks, care duties, communication in family and use of professional 


\section{A preference for hospital care}

In Turkey it was found that $43 \%$ of the gynaecological cancer patients (in cases where cure was no longer an option) preferred to stay in the hospital, $41 \%$ preferred outpatient care and $16 \%$ wished to go home; the main reason for wanting to stay in hospital was the feeling of security [32]. Turkish professionals were more likely to want terminal patients to leave the hospital as they accepted that hospitals cannot cure these patients $[28,64]$. Ersoy and Gundogmus found that "most GPs preferred to hospitalize the patient, even by using force if necessary, in order to keep the patient from harm". Turkish physicians were more inclined to fulfil the wishes of the patients' family than to respect the patients' wishes [54]. In a study performed in the Netherlands, most Turkish and Moroccan patients preferred to die at home, but being in the hospital was preferred if they still hoped for a cure or wanted to relieve the family [26]. Buiting et al. found that immigrants were more likely to die in hospital than Dutch patients [35].

\section{Barriers to the use of professional care}

According to patients, relatives and professionals, the main reasons for immigrants' limited use of professional home care, residential care for the elderly or hospice care were unfamiliarity with the available care facilities and language barriers [33,45,60,77]. Also financial problems and traditional views on family duties sometimes formed barriers to using professional care $[17,23,26,80]$. Relatives' care preferences and feelings of shame were often a deciding factor in the limited use of professional care $[17,47,80]$.

\section{Perspectives on the quality of professional care}

The quality of care was discussed mainly from the perspective of professionals. It was found that the use of hospital care in Turkey was hampered by limited communication between patient and relatives, and limited cooperation among professionals [64]. Another study reported that more than half of the nurses working in an oncology centre in Ankara had experienced inadequate pain management [67]. Furthermore, nurses and physicians working in oncology centres in Morocco felt embarrassed by the lack of resources and limited training in the treatment of cancer-related pain [63].

In the Netherlands, relatives of patients with a Turkish or Moroccan background often felt responsible for the care being given, making them very critical of the professionals' activities $[22,60,65]$. Professionals in the Netherlands felt the insufficient quality of palliative care for immigrant patients was mainly due to communication problems $[18,23,45,60]$.

\section{Findings relating to perspectives regarding end-of-life care and decision making}

Thirty-five studies addressed the perspectives regarding end-of-life care or decisions at the end-of-life. Five topics were mentioned frequently: (1) hope and faith, (2) views regarding euthanasia, (3) withdrawing and withholding treatment, (4) artificial nutrition and continuing to offer food, and (5) involvement in decision-making.

\section{Hope for cure and faith in Allah}

Many studies revealed that Turkish and Moroccan patients often strive for maximum treatment right up to the end of life. For instance, 63\% of the gynaecological cancer patients in the study by Beji et al. (2005) asked for life-sustaining treatments [32]. Patients only refused life-sustaining treatments in cases where the patient was suffering from poor family relationships, pain or depression. Errihani et al. (2008) found that patients with cancer who were not practicing Muslims (49\%) often felt guilty, while active believers commonly accepted cancer as a divine test [51].

In the Netherlands, the keenness among Turkish and Moroccan patients to have life-sustaining treatments was confirmed in a study by De Graaff et al. [18]. Dutch physicians noted that immigrants were more likely than Dutch patients to be offered life-prolonging treatments (20\% vs $12 \%$ ), artificial respiration (38\% vs $16 \%$ ) and cardiovascular medication (30\% vs $11 \%$ ) [35]. Some families related their wish for life-prolonging treatments to their Muslim religion [18,22,59,60]. Some relatives also mentioned the wish to let the patient die with a clear mind, enabling a good start in the hereafter [18].

\section{Perspectives on euthanasia}

In the Netherlands euthanasia is defined as being the termination of life by a doctor at the request of a patient [3]. This also includes physician-assisted suicide. Euthanasia is not taken to mean abandoning treatment if (further) treatment is pointless. In such cases it is considered part and parcel of normal medical practice that the doctor discontinues treatment and lets nature take its course. The same applies to administering large doses of opiates for pain relief whereby one side effect is that death occurs more quickly.

Several studies in Turkey addressed the concept of 'euthanasia', although what respondents meant by this concept varied. One study recorded that Turkish nurses and doctors did not have the same knowledge about the different forms of euthanasia (active euthanasia, passive euthanasia, physician-assisted suicide and involuntary euthanasia) [75]. They were most familiar with passive euthanasia (73.2\% of doctors and $62.6 \%$ of nurses). In a study by $\mathrm{Oz}$, most nurses and physicians (58\%) defined it as "allowing death, leaving patients to die", others 
(17\%) defined it as "passive euthanasia, not active death determined by others", or as "painless, peaceful death" (13\%) [69].

Some Turkish studies suggest that professionals do sometimes get requests to perform euthanasia or "to make death easy". The number of professionals that had been asked to do so varied (see Table 3), ranging from $8 \%$ of the professionals in the study by Turla et al. [76] to $34 \%$ of the oncologists in the study by Mayda et al. [62]. The different percentages may be related to the above-mentioned differences and/or a lack of clarity in definitions of euthanasia or "making death easy". The responses to a patient's request for euthanasia or "making death easy" also varied (see Table 3). Most professionals in Turkey were disapproving of any form of legalization of euthanasia. The reasons for objecting to legalization were fear of abuse, ethical principles, religious beliefs and personal values [62,75,76].

No Moroccan studies about views on euthanasia were found. But in the Netherlands, a study concluded that patients and families with a Dutch background were more likely to request euthanasia (25\% and $18 \%$ ) than migrants and their relatives (3\% and 4\%) [35].

\section{Withdrawing or withholding life-prolonging treatments}

One study found that older Turkish patients often opted for life-prolonging treatments; even when they longed to die, they accepted life-prolonging proposals from physicians as their relatives wanted them to live as long as possible [31]. Another study noted that $38 \%$ of the Turkish physicians had advised patients not to start life-prolonging therapy and 51\% had withdrawn treatment [62]. Although withdrawing treatment was often felt to be reprehensible, professionals also admitted it to be part of their job. In one study, for example, $40 \%$ of the Turkish intensive-care nurses justified withdrawing treatment when there was no medical benefit [27], and another study [75] found that $40 \%$ of the intensive-care physicians had discontinued treatment in patients with an incurable disease on more than one occasion. Withdrawing treatment was more difficult than not initiating the treatment [40], and was often a matter for discussion. $84 \%$ of the Turkish physicians in the study of Ersoy and Gundogmus found withholding treatment acceptable if the patient wished for it, but only $13 \%$ would respect the patients' wishes if relatives contested this [54]. Ilkilic described how Turkish parents living in Germany wished to continue mechanical respiration of their incurably ill child, referring to their religious duties, while the German physicians judged the situation to be medically hopeless [56].

\section{Continuing to offer food and artificial nutrition}

Several studies reported that Turkish patients often expect to be fed until the very end. In one study $75 \%$ of health staff disagreed with the statement that, nutrition should be stopped if a patient wants euthanasia [58], while $68 \%$ of the nurses in another study agreed that artificial nutrition should always be continued [27].

No Moroccan studies were found on this topic, but in the Netherlands it was reported that Turkish and Moroccan immigrant families preferred the feeding of their terminally ill relatives to continue [18]. Besides, it was found that terminally ill immigrants in the Netherlands were more likely to be given artificial nutrition and hydration than comparable native Dutch patients [35].

\section{Involvement in end-of-life decisions}

In Turkey, many cancer patients wanted to be involved in decisions about treatments (79\% of the sample in one study, for example [49]), but use of written advanced directives was low and do-not-resuscitate orders were often only given verbally $[57,79]$. In practice, relatives were often the ones making the decision in end-of life care. In one study, $54 \%$ of the Turkish oncologists said patients should decide about euthanasia and $42 \%$ said families and doctors should decide jointly [62]. The strong involvement of relatives in decision making is also described by Iyilikçi et al. [57]. However, some studies also pointed to preferences for taking decisions jointly: Iyilikçi et al., for example, concluded that most anaesthesiologists in Turkey wanted decision by consensus [57]. Moreover, Turla et al. reported that $63 \%$ of the professional care providers wished that "both the physician and the family" could decide [76]. Yet other authors remarked that decisions were often still the domain of physicians $[31,49,71,74]$.

This topic was not addressed in studies performed in Morocco, but Dutch research indicated that Turkish and Moroccan relatives sometimes did not want any medical end-of-life decisions to be taken as the end of life ought to be in the hands of Allah [22]. In other studies relatives declared that they should be the main party in the decision-making and not the patient, as the latter deserved rest and had to remain hopeful until the end $[18,23]$. However, this contrasted with the dominant view of Dutch professionals that decision making should always reflect the preferences of the individual patient.

\section{Findings relating to communication}

Thirty-seven studies addressed the communication between Turkish and Moroccan patients and relatives and their care providers in end-of-life care. Four topics were mentioned frequently: (1) communication about diagnosis and prognosis, (2) communication about pain, sorrow and mental problems, (3) language barriers and (4) communication patterns within the family. 


\section{Communication about diagnosis and prognosis}

Most studies on communication about diagnosis and prognosis were performed in Turkey. In this country the percentages of patients unaware of their diagnosis varied (see Table 4), ranging from 16\% [48] to 63\% [37]. The wish to be informed varied from $66 \%$ of the patients with diverse diagnoses [48] to $85 \%$ of patients diagnosed with cancer [31,49]. Relatives may form barriers to informing patients about a bad diagnosis or prognosis. In one study, it was found that many relatives (66\%) did not want patients to be informed because they would be upset or would not want to know it [71]. Another study found that $39 \%$ of the relatives adhered to this opinion, $48 \%$ felt that patients should be informed, and 13\% were hesitant [68]. The differences between the findings might be due to the differences in the formulation of the questions.

The likelihood of Turkish physicians informing patients increased with an increase in the patient's socio-economic status and educational level [37], and also depended on the type of illness and on relatives' preferences [22,54]. Although $93 \%$ of the physicians in the study by Pelin and Arda [74] thought that patients should be informed, $30 \%$ chose to inform relatives. While $67 \%$ of the physicians in another study would tell the truth to the patient, $8 \%$ preferred to inform relatives and $12 \%$ would ask relatives for their consent before talking to the patient [54]. However, $68 \%$ of the physicians in a third study said they would tell the patient the diagnosis first before informing their relatives [31]. Professionals' attitudes were influenced by their skill in bringing bad news and by the stage of the disease. Trained and more experienced physicians were more likely to inform the patient $[72,74]$. Furthermore, $76 \%$ of nurses would tell the truth to a breast-cancer patient asking for a diagnosis [53], while $96 \%$ would not inform a patient in the terminal phase [67].

In Morocco, 33\% of cancer patients did not know their diagnosis, while relatives were informed in $89 \%$ of cases [52]. In the Netherlands, some Turkish and Moroccan patients were not informed $[17,33,45,59]$. Elderly patients would not talk about life-threatening illnesses [26], whereas younger patients often preferred to be informed but would not inform all their relatives [59]. The arguments used were that telling the truth would hasten a patients' death and that information might stir gossiping in the community [56,59]. In addition, Turkish and Moroccan relatives disliked the direct way Dutch care providers informed patients $[18,23,26]$. The influence of relatives in communication is amplified by their role as interpreters $[18,33,59]$.

\section{Communication about pain, sorrow and mental problems}

Several studies noted that communication with a patient at the end of life is often problematic. For example, one study found that Turkish patients often did not want to talk about pain as they feared becoming dependent on analgesics and did not want to upset their relatives [30]. Atesci et al. found more psychiatric disorders among patients aware of their diagnosis than among patients who were not informed, but this might be related to inadequate information so the authors concluded that physicians should teach patients to cope with the information [29]. Turkish nurses felt embarrassed because they could not express their feelings of empathy for dying people [64].

McCarthy et al. reported that Moroccan physicians and nurses did not have the means to detect or assess pain as their patients did not indicate pain, either physically or verbally [63]. Studies in the Netherlands report that, according to patients and relatives, immigrant patients would often not talk about psychological problems, depression or dementia $[23,66,77]$.

\section{Language barriers}

In a Moroccan study it was noted that $25 \%$ of the patients spoke only Berber. Their insufficient knowledge of Arabic caused enormous difficulties in communication between patients and professionals [50].

According to patients, relatives and care providers in the Netherlands, language barriers were often tackled with the help of relatives and bilingual interpreters or other intermediary professionals $[17,18,60]$. Many elderly Turkish patients living in the Netherlands said they wanted Turkish-speaking staff [33]. This was sometimes arranged [77]. But involving staff of Turkish or Moroccan origin could also amplify undesirable social control within the community [26,59]. In another immigrant country, namely Germany, it was noted that language barriers impeded physicians in taking joint decisions with Turkish patients - they could not understand the discussions between patients and interfering relatives [56].

\section{Communication within the family and within the community}

Many studies suggested that communication problems in palliative care were sometimes related to the social patterns within the family. For example, one study concluded that according to patients, the dominance of families in patient support often resulted in low disclosure rates in Turkey [34]. In a study performed among Turkish and Moroccan health advisors in the Netherlands, it was found that Turkish and Moroccan immigrant families seldom talk about illness and the sorrow it causes because they wanted to avoid gossiping in the community [59]. According to elderly immigrants, immigrant families were facing a dilemma: the ideal of children taking care of parents prevented them from discussing care needs openly 
and from looking for other sources of care [23]. The explanations given for limited communication within the family were immigrants' limited experience with dying, as the previous generation was cared for in their country of origin [18], a lack of knowledge about the facilities in the host country [26] and religious traditions: the obligation to provide care, and pressure from the community, be it Muslims $[17,80]$ or Christians [55].

\section{Discussion}

This systematic literature study describes the care experiences and care perceptions of incurably ill Turkish and Moroccan patients, their relatives and care professionals, and their communication with each other.

The extensive searches resulted in 64 relevant references dealing with 57 studies. Eighteen of the 57 studies concerned family care. These studies showed that relatives considered family care as a duty, although the care burden was often too high for the female relatives in particular. This conclusion was mainly based on studies of Turkish and Moroccan immigrant families living in the Netherlands as family care has never been a central issue in the studies in the countries of origin (Turkey and Morocco).

Twenty-five studies addressed perceptions regarding professional care. A lot of Turkish and Moroccan incurably ill patients and their relatives preferred hospitalization, which was related to their search for security and a cure right up to the end. In addition, the limited use of professional home care and residential elderly care was also due to financial problems, preferences for family care, communication problems and the insufficient quality of care. However, it should be noted that the preferences for certain kinds of care will depend on the availability of alternatives. This could explain why preferences for hospital care were addressed mainly in Turkish studies, while the thresholds to using professional home care, residential care for the elderly and hospice care were mainly studied among immigrants in the Netherlands.

On the basis of 35 studies addressing the perspectives concerning end-of-life care and decision making, we can conclude that patients and family often wanted lifeprolonging treatments until the very end. Decisions to withdraw or withhold treatments were often contested by relatives and not openly discussed with the patient. Hope for a cure and the desire for life-prolonging treatments were related to faith in Allah. Patients' and relatives' focus on life prolongation might be a reason for the fact that perceptions regarding euthanasia and views on withdrawing or withholding treatments were only investigated in studies among professionals. These studies - mainly performed in Turkey - showed that, in general, withdrawing treatment and euthanasia were disapproved of. But the findings of these studies were not congruent in all regards: some studies emphasized a preference for shared decision-making, while other studies noted that decisions were still often made by physicians or relatives, with the patients' opinion not being taken into account.

Thirty-seven studies addressed communication. Incurably ill patients with a Turkish or Moroccan background were not always informed about their diagnosis although professionals frequently held the opinion that patients should be informed. Relatives often prevented disclosure as they felt this might upset their patient, even when patients wished to know the truth. Additionally, communication about pain and psychological symptoms was often problematic because patients were reluctant to talk, fearing the use of analgesics and wanting to avoid upsetting their relatives. Language barriers and the dominance of the family reinforced the often complex communication patterns. Communication was often hampered by language barriers (in the Netherlands, but also in Morocco) or the relatives' dominant role.

A limitation of this review is that we could not synthesize the data of underlying studies in all regards because of the variety of instruments and research questions. Findings were frequently not in agreement, even on topics that have been studied rather intensively (such as informingpatients about the diagnosis and prognosis), due to diverging research questions, designs and instruments.

Account must also be taken of the fact that the representativeness of the results is sometimes open to discussion, as the response rates in the quantitative studies were often unknown or low, and the qualitative studies had small samples.

Another limitation is that the majority of the studies included in the review concerned professionals in Turkey or immigrants' relatives in the Netherlands. In general the patient perspective was under-represented, and there were only a limited number of studies in Morocco, hampering comparisons between Turkish and Moroccan subjects. In addition, we cannot draw conclusions on the basis of this review as to whether the specific experiences and perceptions of Turkish and Moroccan immigrants are rooted in either their past in the country of origin or in their present situation as immigrants in a foreign country. Time may be an important factor, both for Turkish, Moroccan and Dutch professionals and for Turkish and Moroccan patients and their relatives. As VPTZ [26] indicated, a culturally sensitive approach may lead to an acceptance of the do-not-tell wishes of some elderly first-generation immigrants, but will not suit the information needs of second-generation immigrants.

This review confirms the view that palliative care should take account of the specific cultural characteristics of patients and relatives. In the Introduction section 
we referred to studies indicating that poverty, family systems, religious customs and traditional care influenced the care perceptions of patients in non-Western lowresource countries. This corresponds with our findings on incurably ill patients with a Turkish and Moroccan background. In addition, we referred to studies showing that palliative care for immigrants in Western countries is often hindered by language barriers and health illiteracy, resulting in an important role for interpreting relatives. Comparable communication features were found in this review dealing specifically with people with a Turkish or Moroccan background.

A question that subsequently arises is whether our findings on Turkish and Moroccan patients and families can also be applied to other immigrant groups in the Netherlands, such as Moluccan, Chinese, Surinamese and Antillean immigrants, and refugees from various countries. No unequivocal conclusions can be drawn on the basis of this review as the immigrant groups mentioned differ from Turkish and Moroccan immigrants in terms of of the countries they come from, when and why they immigrated to the Netherlands, their reception in the Netherlands and Dutch language skills. Future research on care beliefs, needs and communication processes in the palliative care phase for other immigrant groups in the Netherlands could bolster and extend the current insights.

\section{Conclusions}

This systematic literature study confirms the findings of our earlier empirical studies, showing that family care for incurably ill patients is considered a duty, even when this care becomes a severe burden for the central female family caregiver in particular. Hospitalization is preferred by a substantial proportion of patients and relatives, since they often strive for cure right up to the end and focus strongly on life-prolonging treatments. Relatives often prevent disclosure as they feel this might upset their patient, even when patients wish to know the truth. Medical end-of life decisions, such as withdrawing and withholding treatment, are seldom discussed with the patient. In addition, communication about pain or mental issues is limited. Language barriers and the dominance of the family may amplify communication problems. Apart from these concrete findings our review revealed that the perspectives on care and communication involving incurably ill Turkish and Moroccan patients not only reflect their cultural background but also their social situation. This dual focus enables palliative care policy makers and practitioners to take account of the social and economic circumstances of each family, the mental and physical barriers preventing them from engaging professional care, the religious and legal considerations influencing their decision making and their communication capacities.

\section{Additional file}

\section{Additional file 1: Search sources.}

\section{Competing interests}

The authors declare that they have no competing interests.

\section{Authors' contributions}

FMG and ALF designed the study; FMG and PM performed all phases of the systematic review; WD and ALF were involved in the methodological assessment; FMG wrote initial draft of this paper and PM, WD and ALF gave comments on all following versions and the final version. All authors read and approved the final manuscript.

\section{What is already known about the topic?}

The international literature has shown that palliative care for non-Western patients can be problematic because of inadequate pain relief and medication, as wells as family systems and religious practices. In addition, palliative care for ethnic minorities in Western countries can be limited by languages barriers, ignorance about specified facilities, discrimination and criticism from their community.

\section{What the paper adds}

Our review looking at Turkish and Moroccan patients demonstrates that the 'family' factor is crucial. Palliative care for Turkish and Moroccan patients has to take account of the fact that family care is dominant and that the desire for a cure leads to a preference for hospital care, even when cure is no longer an option. Efforts to inform incurably ill patients about their diagnosis and prognosis, and share decisions regarding medical end-of life decisions are often contested by relatives, who want to protect the patients and keep hope alive. Even when patients want to know the truth, they are often protected by their relatives.

\section{Acknowledgements}

The research presented was financially supported by ZonMw, The Netherlands Organization for Health Research and Development.

\section{Author details}

${ }^{1}$ Medical Anthropology \& Sociology Unit, University of Amsterdam, Oudezijds Achterburgwal 185, 1012DK, Amsterdam, the Netherlands. ${ }^{2}$ MUTANT, Projects for innovation and diversity, The Hague, the Netherlands. ${ }^{3}$ NIVEL

(Netherlands Institute for Health Services Research), PB 15683500 BN, Utrecht, the Netherlands. ${ }^{4} \mathrm{VU}$ University Medical centre (EMGO+), PB 7057 1007 MB, Amsterdam, the Netherlands. ${ }^{5}$ Pharos (Knowledge and advisory centre on refugees, migrants and health), PB 133183507 LH, Utrecht, the Netherlands.

Received: 27 February 2012 Accepted: 13 September 2012 Published: 18 September 2012

\section{References}

1. Centeno C, Clark D, Lynch T, Racafort J, Praill D, De LIma L, et al: Facts and indicators on palliative care development in 52 countries of the WHO European region: results of an EAPC task force. Palliat Med 2007, 21:463-471.

2. Francke $A L$, Kerkstra A: Palliative care services in the Netherlands. Patient Educ Couns 2000, 41:23-33.

3. Francke AL: Palliative care for terminally ill patients in the Netherlands. Dutch Government Policy. The Hague: Dutch Ministry of Health, Welfare and Sport; 2003.

4. Selman LE, Beattie JM, Murtagh FE, Higginson IJ: Palliative care: Based on neither diagnosis nor prognosis, but patient and family need. Commentary on Chatoo and Atkin. Soc Sci Med 2009, 69:154-157.

5. WHO: Palliative care. 2011. Available from: http://www who int/cancer/ palliative/en/ (accessed: 2011).

6. Bingley A, Clark D: A comparative review of palliative care development in six countries represented by the Middle East Cancer Consortium (MECC). J Pain Symptom Manage 2009, 37:287-296. 
7. Chaturvedi SK: Ethical dilemmas in palliative care in traditional developing societies, with special reference to the Indian setting. J Med Ethics 2008, 34:611-615.

8. Macpherson CC: Healthcare development requires stakeholder consultation: palliative care in the Caribbean. Camb Q Healthc Ethics 2006, 15:248-255.

9. McGrath P, Vun M, McLeod L: Needs and experiences of non-Englishspeaking hospice patients and families in an English-speaking country. Am J Hosp Palliat Care 2001, 18:305-312.

10. Kreps GL, Sparks L: Meeting the health literacy needs of immigrant populations. Patient Educ Couns 2008, 71:328-332.

11. Gunaratnam $Y$ : Intercultural palliative care: do we need cultural competence? Int J Palliat Nurs 2007, 13:470-477.

12. Smith AK, Sudore RL, Perez-Stable EJ: Palliative care for Latino patients and their families: whenever we prayed, she wept. JAMA 2009, 301:1047-1057.

13. Gunaratnam Y: Eating into multiculturalism: hospice staff and service users talk food, 'race', ethnicity, culture and identity. Crit Soc Pol 2001, 21:287-310

14. Gunaratnam Y: From competence to vulnerability: care, ethics, and elders from racialized minorities. Mortality 2008, 13:24-41.

15. Owens A, Randhawa G: 'It's different from my culture; they're very different': Providing community-based, 'culturally competent' palliative care for South Asian people in the UK. Health Soc Care Community 2004, 12:414-421.

16. Worth A, Irshad T, Bhopal R, Brown D, Lawton J, Grant E, et al: Vulnerability and access to care for South Asian Sikh and Muslim patients with life limiting illness in Scotland: prospective longitudinal qualitative study. BMJ 2009, 338:b183.

17. de Graaff F, Francke AL: Home care for terminally ill Turks and Moroccans and their families in the Netherlands: carers' experiences and factors influencing ease of access and use of services. Int J Nurs Stud 2003, 40:797-805.

18. de Graaff F, Francke AL, Van den Muijsenbergh ME, van der Geest S: Communicatie en besluitvorming in de palliatieve zorg voor Turkse en Marokkaanse patiënten met kanker [Communication and decision making in the palliative care for Turkish and Moroccan patients withn cancer]. Amsterdam: UvA, Spinhuis; 2010.

19. CBS: Jaarrapport Integratie 2010 [2010 Annual Report on Integration]. The Hague/Heerlen: Centraal Bureau voor de Statistiek; 2010.

20. de Graaff F, Francke AL: Zorg voor Turkse en Marokkaanse ouderen in Nederland [Care for elderly Turkish and Moroccan immigrants in the Netherlands]. Verpleegkunde 2002, 17:131-139.

21. Hawker S, Payne S, Kerr C, Hardey M, Powell J: Appraising the evidence: reviewing disparate data systematically. Qual Health Res 2002, 12:1284-1299.

22. ACTIZ: Interculturele palliatieve zorg: Vraaggericht en individueel [Intercultural palliative care: responsive to requirements and individualized]. Utrecht: Actiz; 2009.

23. NOOM: Bagaimana - Hoe gaat het? Een verkenning van kwetsbaarheid bij oudere migranten [Bagaimana- How are you? An exploratory study of the vulnerability of elderly immigrants]. Utrecht: NOOM; 2009.

24. Signaleringscommissie Kanker van KWF Kankerbestrijding: Allochtonen en kanker; Sociaal-culturele en epidemiologische aspecten [immigrants and cancer; socio-cultural and epidemiological aspects. Report by the Dutch Cancer Society's Signalling Committee]. Amsterdam: KWF; 2006.

25. VPTZ: "Gaat u het gesprek aan?" - Goede zorg voor stervenden van allochtone afkomst. Publieksversie eind-rapportage [Does this conversation concern you?" Good quality care for dying immigrants. Version of final report for the general public]. Bunnik: VPTZ; 2008.

26. VPTZ: "Gaat $u$ het gesprek aan?" Eind-rapportage ["Does this conversation concern you?"]. Bunnik: VPTZ; 2008.

27. Akpinar A, Senses MO, Aydin ER: Attitudes to end-of-life decisions in paediatric intensive care. Nurs Ethics 2009, 16:83-92.

28. Aksoy S: End-of-life decision making in Turkey. In End-of-life decision making: a cross-national study. Edited by Blank R, Merrick J. Cambridge: MIT Press; 2005.

29. Atesci FC, Baltalarli B, Oguzhanoglu NK, Karadag F, Ozdel O, Karagoz N: Psychiatric morbidity among cancer patients and awareness of illness. Support Care Canc 2004, 12:161-167.

30. Bagcivan G, Tosun N, Komurcu S, Akbayrak N, Ozet A: Analysis of patientrelated barriers in cancer pain management in Turkish patients. J Pain Symptom Manage 2009, 38:727-737.
31. Balseven Odabasi A, Ornek Buken N: Informed consent and ethical decision making in the end of life: Hacettepe example. Klinikleri J Med Sci 2009, 29:1041-1054.

32. Beji NK, Reis N, Bag B: Views of patients with gynecologic cancer about the end of life. Support Care Canc 2005, 13:658-662.

33. Betke P: Divers sterven. ..: een explorerend onderzoek naar palliatieve zorg in een verpleeghuis aan Turkse ouderen [Diveristy in dying. ...: an exploratory study of palliative care for elderly Turkish immigrants in a nursing home]. Rotterdam: Erasmus Universiteit; 2005.

34. Bozcuk H, Erdogan V, Eken C, Ciplak E, Samur M, Ozdogan M, et al: Does awareness of diagnosis make any difference to quality of life? Determinants of emotional functioning in a group of cancer patients in Turkey. Support Care Canc 2002, 10:51-57.

35. Buiting $H$, Rietjens JA, Onwuteaka-Philipsen BD, van der Maas PJ, van Delden JJ, Van Der Heide A: A comparison of physicians' end-of-life decision making for non-western migrants and Dutch natives in the Netherlands. Eur J Publ Health 2008, 18:681-687.

36. Buiting H, Rietjens J, Onwuteaka-Philipsen B, van der Maas P, van Delden J, Van Der Heide A: Medische besluitvorming in de laatste levensfase: Een vergelijking tussen niet-westerse migranten en autochtonen in Nederland [Medical decision making in the final phase of life: a comparison between non-Western immigrants and ethnic Dutch in the Netherlands]. Nederlands: Tijdschrift voor Palliatieve Zorg; 2009:9.

37. Buken ND: Truth telling information and communication with cancer patients in Turkey. J Int Soc Hist Islamic Med 2003, 2:31-37.

38. Celik S, Gurkan S, Atilgan Y: A brief report of research: care activities for deceased patients of intensive care nurses at a private hospital in Istanbul, Turkey. Dimens Crit Care Nurs 2009, 28:232-236.

39. Cetingoz R, Kentli S, Uruk O, Demirtas E, Eyiler F, Kinay M: Turkish people's knowledge of cancer and attitudes toward prevention and treatment. J Canc Educ 2002, 17:1755-1758.

40. Cobanoglu N, Algier L: A qualitative analysis of ethical problems experienced by physicians and nurses in intensive care units in Turkey. Nurs Ethics 2004, 11:444-458.

41. Cohen J, Marcoux I, Bilsen J, Deboosere P, van der Wal G, Deliens L: European public acceptance of euthanasia: socio-demographic and cultural factors associated with the acceptance of euthanasia in 33 European countries. Soc Sci Med 2006, 63:743-756.

42. de Graaff F: Tips voor terminale thuiszorg voor Turkse en Marokkaanse ouderen [Tips for terminal home care for elderly Turkish and Moroccan immigrants]. Utrecht: NIVEL; 2002.

43. de Graaff F, Francke AL: Terminale thuiszorg voor Turkse en Marokkaanse ouderen [Terminal home care for elderly Turkish and Moroccan immigrants]. TSG 2003, 81:24.

44. de Graaff F, van Hasselt T, Francke AL: Thuiszorg voor terminale Turkse en Marokkaanse patiënten: ervaringen en opvattingen van naasten en professionals [Home care for terminally ill Turkish and Moroccan patients: the experiences and views of family and professionals]. Utrecht: NIVEL; 2005.

45. de Graaff F, Francke AL: Barriers to home care for terminally ill Turkish and Moroccan migrants, perceived by GPs and nurses: a survey. BMC Palliative Care 2009, 8:3.

46. de Graaff F, Francke AL, Van den Muijsenbergh ME, Van der Geest S: 'Palliative care': a contradiction in terms? A qualitative study among cancer patients with a Turkish or Moroccan background, their relatives and care providers. BMC Palliat Care 2010, 9:19.

47. de Meyere V: Verwerking van borstkanker bij Turkse vrouwen. Op zoek naar een cultureel aangepaste ondersteuning [How Turkish women deal with breast cancer. A search for culturally adapted support]. Cultuur Migratie Gezondheid 2004, 1:2-13.

48. Demirsoy N, Elcioglu O, Yildiz Z: Telling the truth: Turkish patients' and nurses' views. Nurs Sci Q 2008, 21:75-79.

49. Erer $S$, Atici $E$, Erdemir AD: The views of cancer patients on patient rights in the context of information and autonomy. J Med Ethics 2008, 34:384-388.

50. Errihani H, Mrabti H, Boutayeb S, Ichou M, El Mesbahi O, El Ghissasi I, et al: Psychosocial profile of Moroccan breast cancer patients. Ann Oncol 2006, 17:ix280.

51. Errihani H, Mrabti H, Boutayeb S, El Ghissasi I, El Mesbahi O, Hammoudi M, et al: Impact of cancer on Moslem patients in Morocco. Psychooncology 2008, 17:98-100.

52. Errihani H, Mrabti H, Sbitti Y, El Ghissasi I, Afqir S, Boutayeb S, et al: Caractéristiques psychosociales des patients cancéreux marocains: étude 
de 1000 cas recrutés à l'Institut national d'oncologie de Rabat [Psychosocial and religious impact of cancer diagnosis on Moroccan patients: experience from the national oncology center of Rabat]. Bull Canc (Paris) 2005, 97:461-468.

53. Ersoy N, Goz F: The ethical sensitivity of nurses in Turkey. Nurs Ethics 2001, 8:299-312.

54. Ersoy N, Gundogmus UN: A study of the ethical sensitivity of physicians in Turkey. Nurs Ethics 2003, 10:472-484

55. Groen van de Ven L, Smits C: Aandacht, acceptatie en begrip. Mantelzorg aan ouderen in de Suryoye gemeenschap [Attention, acceptance and understanding. Care for the elderly by friends and family in the Suryoye community]. Cultuur Migratie en Gezondheid 2009, 6:198-208.

56. Ilkilic I: Kulturelle Aspekte bei ethischen Entscheidungen am Lebensende und interkulturelle Kompetenz [Cultural aspects of ethical decisions at the end of life and cultural competence]. Bundesgesundheitsblatt Gesundheitsforschung Gesundheitsschutz 2008, 51:857-864.

57. Iyilikci L, Erbayraktar S, Gokmen N, Ellidokuz H, Kara HC, Gunerli A: Practices of anaesthesiologists with regard to withholding and withdrawal of life support from the critically ill in Turkey. Acta Anaesthesio/ Scand 2004, 48:457-462.

58. Karadeniz G, Yanikkerem E, Pirincci E, Erdem R, Esen A, Kitapcioglu G Turkish health professional's attitude toward euthanasia. Omega J Death Dying 2008, 57:93-112.

59. Koppenol M, Francke AL, Vlems F, Nijhuis H: Allochtonen en kanker. enkele onderzoeksbevindingen rond betekenisverlening, communicatie en zorg [Immigrants and cancer. Some research findings on giving meaning, communication and care]. Cultuur Migratie Gezondheid 2006, 3:212-222.

60. Korstanje M: "Ik had eigenlijk heel veel willen vragen". Mantelzorgers van allochtone patienten in ziekenhuizen ["I really had a lot of questions". Non-professional carers of immigrant patients in hospital]. Cultuur Migratie Gezondheid 2008, 5:24-31.

61. Kumas G, Oztunc G, Nazan AZ: Intensive care unit nurses' opinions about euthanasia. Nurs Ethics 2007, 14:637-650.

62. Mayda AS, Ozkara E, Corapcioglu F: Attitudes of oncologists toward euthanasia in Turkey. Palliat Support Care 2005, 3:221-225.

63. McCarthy P: Managing children's cancer pain in Morocco. J Nurs Scholarsh 2004, 36:11-15.

64. Meric M, Sayligil Elcioglu O: The observations and problems of the nurses providing care for the patients in terminal periods. SENDROM 2004, 16:109-115.

65. Meulenkamp TM, van Beek APA, Gerritsen DL, de Graaff F, Francke AL: Kwaliteit van leven bij migranten in de ouderenzorg. Een onderzoek onder Turkse, Marokkaanse, Surinaamse, Antilliaanse/Arubaanse en Chinese ouderen [Quality of life of immigrants in the care system for the elderly. A study of elderly Turkish, Moroccan, Surinam, Antilles/Aruban and Chinese immigrants]. Utrecht: NIVEL; 2010

66. Mostafa S: Allochtone vrouwen met borstkanker [ Ethnic minority women with breast cancer]. Nijmegen: Radboud Universiteit, afdeling eerstelijnsgeneeskunde; 2009.

67. Oflaz F, Arslan F, Uzun S, Ustunsoz A, Yilmazkol E, Unlu E: A survey of emotional difficulties of nurses who care for oncology patients. Psychol Rep 2010, 106:119-130.

68. Oksuzoglu B, Abali H, Bakar M, Yildirim N, Zengin N: Disclosure of cancer diagnosis to patients and their relatives in Turkey: views of accompanying persons and influential factors in reaching those views. Tumori 2006, 92:62-66.

69. Oz F: Nurses' and physicians' views about euthanasia. Clin Excell Nurse Pract 2001, 5:222-231.

70. Ozcakir A, Uncu Y, Sadikoglu G, Ercan I, Bilgel N: Students' views about doctor-patient communication, chronic diseases and death. Educ Health (Abingdon) 2008, 21:149.

71. Ozdogan M, Samur M, Bozcuk HS, Coban E, Artac M, Savas B, et al: "Do not tell": What factors affect relatives' attitudes to honest disclosure of diagnosis to cancer patients? Support Care Canc 2004, 12:497-502.

72. Ozdogan M, Samur M, Artac M, Yildiz M, Savas B, Bozcuk HS: Factors related to truth-telling practice of physicians treating patients with cancer in Turkey. J Palliat Med 2006, 9:1114-1119.

73. Ozkara E, Hanci H, Civaner M, Yorulmaz C, Karagoz M, Mayda AS, et al: Turkey's physicians' attitudes toward euthanasia: a brief research report. Omega J Death Dying 2004, 49:109-115.
74. Pelin SS, Arda B: Physicians' attitudes towards medical ethics issues in Turkey. J Int Bioethique 2000, 11:57-67.

75. Tepehan S, Ozkara E, Yavuz MF: Attitudes to euthanasia in ICUs and other hospital departments. Nurs Ethics 2009, 16:319-327.

76. Turla A, Ozkara E, Ozkanli C, Alkan N: Health professionals' attitude toward euthanasia: a cross-sectional study from Turkey. Omega J Death Dying 2006, 54:135-145.

77. van den Bosch AF: Baklava \& zoete praatjes; ouder worden in multicultureel Nederland. Een onderzoeksrapport met een positief verhaal over de gezondheidssituatie, het zorggebruik en het vertrouwen in de arts van oudere Turkse Nederlanders. Enschede: Universiteit Twente; 2010.

78. van Wijmen MP, Rurup ML, Pasman HR, Kaspers PJ, Onwuteaka-Philipsen BD: Advance directives in the Netherlands: an empirical contribution to the exploration of a cross-cultural perspective on advance directives. Bioethics 2010, 24:118-126.

79. Yaguchi A, Truog RD, Curtis JR, Luce JM, Levy MM, Melot C, et al: International differences in end-of-life attitudes in the intensive care unit: results of a survey. Arch Intern Med 2005, 165:1970-1975.

80. Yerden I: Zorgen over zorg. Traditie, verwantschapsrelaties, migratie en verzorging van Turkse ouderen in Nederland [Concerns about care. Tradition, relationships, migration and the care of elderly Turkish migrants in the Netherlands]. Amsterdam: Het Spinhuis; 2000

81. Yerden I: Blijf je in de buurt? Zorg bij zorgafhankelijke Turkse ouderen [Can you stay? Care for care-dependant elderly Turkish immigrants]. Cultuur Migratie Gezondheid 2004, 1:28-37.

82. Yerden I, van Koutrike $\mathrm{H}$ : Voor je familie zorgen? Dat is gewoon zo. Mantelzorg bij allochtonen. Mantelzorg bij Antillianen, Surinamers, Marokkanen en Turken in Nederland [Caring for your family? That's just somethinig you do. Care for ethnic minority patients by family and friends. Care for immigrants in the Netherlands from the Antilles, Surinam, Morocco and Turkey]. Purmerend: Primo; 2007

83. Yildirim Y, Sertoz OO, Uyar M, Fadiloglu C, Uslu R: Hopelessness in Turkish cancer inpatients: the relation of hopelessness with psychological and disease-related outcomes. Eur J Oncol Nurs 2009, 13:81-86.

doi:10.1186/1472-684X-11-17

Cite this article as: de Graaff et al:: Perspectives on care and communication involving incurably ill Turkish and Moroccan patients, relatives and professionals: a systematic literature review. BMC Palliative Care 2012 11:17

\section{Submit your next manuscript to BioMed Central and take full advantage of:}

- Convenient online submission

- Thorough peer review

- No space constraints or color figure charges

- Immediate publication on acceptance

- Inclusion in PubMed, CAS, Scopus and Google Scholar

- Research which is freely available for redistribution 